\title{
El Plan de Ordenamiento Territorial (POT) de Cali, una aproximación*
}

\author{
An approach of territorial arrangement \\ of Cali-Colombia
}

\section{Análise e avaliação do plano de uso da terra na Cali - Colombia}

Rafael Vergara Varela*

* Las opiniones expresadas en este documento comprometen únicamente a su autor y no a las entidades involucradas.

** Economista y MSc en Políticas Públicas. Candidato a PhD en Administración de la Universidad del Valle. Profesor de Políticas Públicas y de Gestión Pública, del Programa Académico de Estudios Políticos y Resolución de Conflictos, adscrito al Instituto de Educación y Pedagogía IEP (Univalle). Investigador de los grupos: Derecho, Estado y sociedad, y Gestión y políticas públicas, adscritos a la Facultad de Ciencias de la Administración, Universidad del Valle. Correo electrónico: rafael.vergara@correounivalle.edu.co 


\title{
Resumen
}

En este documento se describe, analiza y evalúa la política pública de desarrollo urbanístico del Plan de Ordenamiento Territorial en la ciudad de Cali (POT, 2000). La incidencia de dicha política pública dentro de la transformación física de la urbe se puede evidenciar a través de un indicador tan elemental como es el precio del suelo urbano -en relación con el mercado de los precios de la tierra urbana, debido a que este factor señalizador de mercado determina las reglas del juego en una sociedad-. Es decir, se tiene una herramienta metodológica en términos de evaluación de estas políticas públicas específicas.

Palabras clave: políticas públicas, evaluación econométrica, precios de la tierra urbana, desarrollo urbanístico, economía urbana.

Clasificación JEL: A12, B23, B41, C01, R12, R52.

\begin{abstract}
This working paper describes, analyzes and evaluates public policy of urban development of the Land Use Plan (POT, 2000) in the city of Cali. The incidence of such public policy within the physical transformation of the city can be showed through as elementary as it is the price of urban land indicator -in relation to the market price of urban land because this factor market signaler determines the rules of the game in a society-. I.e., we have a methodological tool in terms of evaluation of these specific public policies.
\end{abstract}

Keywords: public policies, econometric assessment, urban land prices, urban development, urban economy. 


\section{Sumário}

Este documento descreve, analisa e avalia a política pública de desenvolvimento urbano do Plano de Uso da Terra (POT, 2000), na cidade de Cali. A incidência de tais políticas públicas dentro da transformação física da cidade, pode corroborar e mostrar através de um indicador tão elementar como é o preço do solo urbano (isso, em relação com o mercado dos preços da terra urbana, debido que esste fator sinalizador de mercado determina as regras do jogo na sociedade). Ou seja, você tem uma ferramenta metodológica em termos de avaliação dessas políticas públicas específicas.

Palavras-chave: políticas públicas, avaliação econométrica, os preços dos terrenos urbanos, desenvolvimento urbano, economia urbana, 


\section{INTRODUCCIÓN}

El presente documento analiza desde un enfoque histórico-institucional, el desarrollo urbanístico y la descentralización de la ciudad de Cali. En este sentido, es necesario establecer a qué políticas o instrumentos de tipo normativo responde el Plan de Ordenamiento Territorial (POT, 2000).

Ahora bien, la política pública urbanística del POT dejó implícita la descentralización de actividades urbanas, sean estas, industriales, comerciales o de servicios. Dicha política sirve igualmente como lineamiento de normatividades tales como: el Plan Piloto (1950), el Plan General de Desarrollo (PGD, 1969) y el Plan Integral de Desarrollo de Cali (Pideca, 1980), que planteaban el desarrollo de la ciudad como eje articulador de diversas actividades tanto comerciales, como industriales y de servicios, alejando a Cali de su modelo de monocestrismo nodal hacia una urbe pluricéntrica, trazada por un corredor vial por donde transitaban grandes multitudes poblacionales, debido a las actividades ejecutadas en dicho eje.

En el periodo de 1930-1950, múltiples procesos migratorios, junto con las ideas de la modernización, el proceso de aceleración industrial y el aumento en las tasas de crecimiento demográfico, llevaron a la expansión de la ciudad y a su constitución por un entramado social, económico, político y cultural diverso (Jiménez, 2005, p. 29). Para responder a este contexto, en la década de los cincuenta, Paul Wiesner y José Luis Sert de la firma Town Planning Associates (TPA) formulan un desarrollo lineal paralelo a las montañas, teniendo como base una infraestructura vial de carácter regional, mediante el Plan Piloto de Cali, de acuerdo con la primera norma de planeación urbana en Colombia, la Ley 88 de 1947. Este Plan se adoptó en 1953 por medio del Decreto 702 (Espinosa, 2006, p. 223-224).

Durante los siguientes quince años (19511964), por razones como el periodo de la violencia, hubo intensas migraciones que aumentaron la población Santiago de Cali de 242.000 a 618.000 habitantes, teniendo tasas de crecimiento anual entre 7 y $8 \%$; por lo que para la década de los sesenta fue pertinente un cambio físico que respondiera a las necesidades de la época. Las respuestas a la problemática se orientaron de acuerdo con dos modelos: como expansiones discontinuas dispersas e incontroladas en terrenos agrícolas asilados y sin urbanizar, o como ocurrió hasta las primeras décadas del siglo veinte, agregando áreas aledañas a la traza fundacional, centro principal, para satisfacer el déficit cuantitativo de vivienda mediante un crecimiento compacto (Mosquera, 2011, p. 8).

En los años sesenta, tras tratar de resolver los problemas suscitados por el aumento poblacional, el estancamiento industrial y del sector de la construcción, la ciudad es postulada para ser sede de los Juegos Panamericanos, por lo que se plantea un desarrollo hacia el sur para dotar 
al municipio de unidades y espacios deportivos, lo cual también incidió en la generación de economías a escala que cambiaron no solo los niveles de la calidad de vida y el bienestar de la población, sino a la vez, la composición física y el desarrollo industrial, impactando en la valorizaron los predios (Vergara, 2009). Al finalizar esta década, se ejecutó el Plan General de Desarrollo (PGD), para el cual se partió de un estudio realizado por la Universidad del Valle (1969), en el cual, mediante la Ley de Reilly, se buscaron las zonas de influencia socioeconómica del municipio, planteando la ciudad como una metrópoli regional con zonas de influencia primaria, secundaria y terciaria.

A partir de los fenómenos deportivos, económicos, sociales, políticos y culturales suscitados durante la década de los setenta, la ciudad pasa a modificar su estructura, cambiando de ser mononuclear a policéntrica. Desde entonces presenta una distribución lineal (Yumbo-CaliJamundí), siendo eje articulador, con una expansión hacia el sur debido a las limitaciones físico-ambientales en el norte. Aunque, para las décadas de los ochenta y noventa existen desarrollos tanto en el norte-sur como en el centro tradicional, que palian los inconvenientes de saturación, desconcentración y descentralización.

En este sentido, el diseño de las "centralidades" planteadas por el Plan de Ordenamiento Territorial intenta mostrar una ciudad bajo el mismo concepto de eje articulador, pero con una serie de subcentros que es necesario evaluar para medir el alcance, la efectividad y la eficacia de la norma. Para este caso, se estudia la tendencia de los precios de la tierra urbana y su relación con el desarrollo urbanístico.

Bajo este escenario, el trabajo busca establecer cuál ha sido la incidencia de las políticas públicas de desarrollo urbanístico en la ciudad de Cali como fenómeno de descentralización, es decir, si las políticas públicas han sido eficaces, o si por el contrario, el desarrollo urbanístico responde a las fuerzas del mercado.

Por lo tanto, este documento pretende guiarse a través de la siguientes preguntas; ¿cuál fue la incidencia de la política pública de desarrollo urbanístico (POT 2000) en la ciudad de Santiago de Cali?, así como también, ¿cómo se ha conformado el contexto urbano a través del Plan de Ordenamiento Territorial (POT 2000)?, siendo el (POT 2000) objeto principal de estudio de esta investigación.

Este artículo presenta primero una descripción de las políticas de desarrollo urbano y su marco normativo general; posteriormente, se centra en la descripción de la Ley 388 de 1997, o Ley de Ordenamiento Territorial; y después en el análisis y evaluación del Plan de Ordenamiento Territorial del año 2000, a partir de una aproximación a los instrumentos cuantitativos. 


\section{POLÍTICAS DE DESARROLLO URBANO}

La planeación se conoce como el conjunto de procesos que tienden al ordenamiento de recursos en el futuro posible y deseable. Por ello, los planes de desarrollo introducen per se, la evaluación de las actividades en la cual se sustenta el ordenamiento (Vallderuten, 1999, p. 29). Sin embargo, tanto a nivel nacional como local, las tareas planificadoras tienden a la distribución de ingresos fiscales, sin que esto establezca un modelo para un sector específico.

Por esta razón, en los años noventa se gestó a nivel nacional la Política Urbana del Salto Social, denominada Ciudades y Ciudadanía (Ministerio de Desarrollo Económico, 1995), la cual, a su vez, también fue planteada a través del documento Conpes 2808 de septiembre de 1995 y en la Ley de Desarrollo Territorial (Ley 388 de 1997). El momento coyuntural y estructural en el cual se formuló esta política tuvo como antesala dos fenómenos relevantes en la vida nacional: la Constitución de 1991 y la apertura económica.

Ahora bien, el propósito de la política urbana Ciudades y Ciudadanía, es la ciudad, ya que esta evidencia cómo el sistema económico del país toma cuerpo en cada ciudad, bajo una red urbana que se integra al territorio por medio de un sistema de relaciones urbano-regionales, las cuales, en últimas, generan economías de escala para las regiones. En este sen- tido, la política urbana reconoce el papel primordial de las ciudades a través de dos dimensiones esenciales: la interurbana y la intraurbana. En respuesta a esto, surge la Ley 388 de 1997, como un modelo para el ordenamiento de nuestras ciudades.

Por otra parte, los antecedentes de la ley citada indican, en primer lugar, que en la Ley de Reforma Urbana -Ley $9^{a}$ de 1989-, el Estado adopta un conjunto de mecanismos que apuntan a la intervención de las entidades públicas en relación con el mercado del suelo. Por este motivo, se implementa la promoción de la gestión urbana pública, dentro de un marco de concertación para la gestión mixta o privada. Pese a la existencia de la reforma urbana, la planeación se canalizó a lo físico, lo cual conllevó una doble crisis: la del plan urbano y la de gobernabilidad. La primera consistió en la separación entre los niveles de concepción del plan y de construcción de la ciudad, y la segunda, en respuesta a objetivos o necesidades, teniendo en cuenta a los ciudadanos (Giraldo, 1997).

Por lo tanto, la noción de planeación, desarrollada en las grandes urbes de nuestro país a inicios de la década de los noventa, hizo del código urbano un fin en sí mismo; es decir, desde su ejecución, la norma estaba absolutamente descontextualizada de la realidad social. En la práctica, lo que ha sucedido es la liberación de amplias zonas en las ciudades, en las cuales, son las fuerzas del mercado (los precios) las que determinan las tendencias de cambio. 
Por otra parte, en los últimos cincuenta años, el país vio crecer su población urbana en forma vertiginosa, como consecuencia de migraciones rurales, explicadas en gran parte por el fenómeno de violencia que se ha generado en el territorio nacional. Y esta masa de emigrantes presiona en las grandes ciudades por la solución de necesidades insatisfechas. Por ello, los fenómenos apremiantes en la solución a esas necesidades hicieron que las entidades territoriales asumieran su responsabilidad con el desarrollo urbano. Ante estos hechos, surge el derecho urbanístico para la solución de problemas que se generan en el desorden del desarrollo de las ciudades.

Cabe anotar que los antecedentes constitucionales del derecho urbanístico son más bien recientes ${ }^{1}$. Así, tenemos que la Constitución de 1886 no generó ninguna articulación debido a que la sociedad era rural, lo que determinaba que la distribución de la propiedad de la tierra ocupara un mayor interés en el contenido de los preceptos constitucionales. Sin embargo, la reforma de 1936 consagró la función social de la propiedad (art. 30), abriendo la posibilidad al Estado de desarrollar un papel en el ordenamiento urbano, ya que concede a la propiedad el predominio del interés colectivo sobre el interés particular. En ese mismo orden, la reforma de 1968 se basó en el concepto del Estado (benefactor), capaz de determinar los lineamientos para seguir en el campo económico, con la posibilidad de limitar los derechos como el de la propiedad, en caso de rebelarse contra el postulado constitucional que impone el cumplimiento de una función social.

No obstante, las normativas anteriores a la Ley $9^{a}$ de 1989 se caracterizaron por su alto grado de dispersión y su poca claridad en torno a los objetivos, ya que estos respondían a asuntos internos en las ciudades y no a la lógica de un planeamiento en torno a los usos del suelo. Por eso, su aplicación tendía a un tipo de administración de corte inmediatista sobre la función de intereses particulares, siendo inequitativa desde el punto de vista social, jurídico y económico. Entre estas reglamentaciones se encuentran: la Ley 14 de 1985, la cual determinó la adquisición de terrenos para empresas de servicios por motivos de utilidad pública; seguidamente, la Ley 137 de 1985 estableció la dotación de vivienda para la población urbana, y dispuso, por ende, el crecimiento de las ciudades. Así mismo, el Código de Régimen Municipal incorporó un capítulo al tema de los planes de desarrollo urbano.

En efecto, la Ley $9^{\text {a }}$ de 1989, o Ley de Reforma Urbana, consagró entre otros, los siguientes principios: defender el derecho a la ciudad para todos los ciudadanos, superar la informalidad en las relaciones comunidad-ciudad, introducir

\footnotetext{
En la exposición de estas normas constitucionales, se tuvieron en cuenta los artículos y textos de Fabio Isaza Giraldo, los cuales se consideran relevantes para este documento.
} 
factores de racionalidad en el diseño de centros urbanos, acelerar los procesos para el desarrollo urbano, y la defensa del espacio público, con lo cual se atacó la crisis de la ciudad convirtiéndola en una herramienta de gestión local (Giraldo, 1989). En síntesis, la Ley $9^{a}$ se convirtió en la expresión de la voluntad política encaminada a ordenar el desarrollo de los municipios.

Adiferencia de la Constitución del 86, y de las reformas mencionadas, la Constitución de 1991 contiene disposiciones expresas sobre el derecho urbanístico, a saber: "es deber del Estado velar por la integridad del espacio público"; "las entidades públicas regularán la utilización del suelo y del espacio aéreo en defensa del interés común"; "cobrarán la plusvalía generada por la acción urbanística" (art. 82). Así mismo, el artículo 334 establece la intervención del Estado en el uso del suelo (Constitución Política, 1991).

$\mathrm{Al}$ respecto, entre los elementos relevantes de la Constitución de 1991, como la descentralización y las transformaciones en el entorno jurídico, económico y político, en ese sentido se exigió, además, la actualización de las normas urbanísticas contenidas en la Ley $9^{\mathrm{a}}$ de 1989, generándose un marco más integral de acción en la política pública urbana. Ahora bien, hay que anotar que esta ley mostraba limitaciones en torno a los precios del suelo, de modo que las ciudades generaban, entre otras complejidades, altos niveles de marginalidad, segregación urbana, problemas de exclusión, invasiones, desorden en el crecimiento urbano, falta de dotación e infraestructura de servicios (públicos, educativos, de salud, de seguridad, etc.), altos grados de hacinamiento y deterioro de la calidad de vida y del bienestar social, factores estos que llevaron a la reestructuración de dicha norma.

\section{LEY DE DESARROLLO TERRITO- RIAL (LEY 388 de 1997)}

Como bien se planteó en el párrafo anterior, esta Ley de Desarrollo Territorial pretendió mejorar los mecanismos previstos en la Ley $9^{\text {a }}$ de 1989 , con las disposiciones constitucionales, en especial las contenidas en los artículos 80 , $82,313,334$ y con las leyes 152 de 1994 y 188 de 1995. Además fortaleció el proceso de descentralización y la autonomía municipal que consagra al municipio como célula fundamental del Estado, dentro del proceso de construcción y modificación del espacio urbano ${ }^{2}$.

Aunque, en la realidad, estas reformas habían posibilitado una gestión integral de la ciudad, la rapidez con que se realizaron conllevó un inmenso atraso en torno a las capacidades de gestión de las localidades, las regiones y la nación. Se nota en estos años que las acciones exclusivamente sectoriales y la falta de coordinación institucional han sido poco

\footnotetext{
2 Esta ley armoniza con las administraciones locales en torno a una creciente autonomía política y administrativa con competencias en torno al gasto y la gestión urbana.
} 
favorables al desarrollo y planificación urbana, lo cual se traduce en crisis de gobernabilidad del espacio urbano. La Ley 388 hizo énfasis en la participación de las entidades nacionales en el desarrollo urbano mediante las concertaciones en el marco de la política pública urbana, articulando proyectos de gran impacto en las ciudades. En síntesis, esta ley ${ }^{3}$ se propuso alcanzar los siguientes objetivos:

- Primero, actualizar las disposiciones de la Ley $9^{a}$ de 1989 con las normas establecidas en la Constitución Política, en especial la Ley del Plan de Desarrollo, la Ley de Áreas Metropolitanas y la Ley de Medio Ambiente.

- Segundo, promover el ordenamiento del territorio, el uso racional del suelo y la defensa del patrimonio ecológico.

- Tercero, garantizar la utilización del suelo, los derechos constitucionales a la vivienda, los servicios públicos domiciliarios y los servicios públicos.

- Cuarto, facilitar las acciones urbanas que confluyan en la gestión de la política urbana.

- Quinto, desarrollar los mecanismos de gestión del suelo, reajuste de tierras, a través de procesos de concertación públicos y privados.

Mediante la consecución de estos objetivos se entienden aspectos legales como la reforma urbana, la planeación y la gestión del suelo. Ahora bien, los principios jurídicos que fundamentan la ley expuesta son los siguientes:
1. La función social y ecológica de la propiedad: definida por el artículo 58 de la Constitución, el cual delimita el ejercicio de los derechos de propiedad. Este principio otorga a las autoridades municipales la facultad de decretar el plan de ordenamiento territorial POT.

2. La prevalencia del interés general sobre el particular: establecida en el artículo $1^{\circ}$ de la Carta Magna, otorga a las autoridades la facultad de intervenir sobre el uso y destino de la propiedad sobre la base del POT.

3. La distribución equitativa de las cargas y beneficios: es el mecanismo más democrático entre la sociedad y los propietarios frente a las normas urbanísticas. Por lo tanto, esto indica que deberán repartirse en forma equitativa las plusvalías, costos o beneficios dictaminados por el POT.

4. La función pública del urbanismo legitima a la Administración pública como la única instancia con poder legal para dirigir, intervenir y controlar las acciones urbanísticas, a través de las determinaciones del POT.

5. La participación democrática de los ciudadanos fomenta el ejercicio de las actividades de la acción urbanística, para asegurar la eficacia de las políticas públicas en relación con el ordenamiento del territorio.

Así mismo, esta ley armoniza el plan de ordenamiento territorial con el plan de desarrollo municipal, dado que el POT define a medio y largo plazo un modelo

3 Dicha ley constituye una importante acción política e institucional que opera mediante la participación privada para alcanzar la función social, en términos de costos y beneficios. 
de ocupación del territorio. Por lo tanto, los planes de desarrollo de los municipios deben tener en cuenta este modelo para la definición de programas y proyectos de inversión en términos de políticas públicas.

INSTRUMENTOS DE PLANIFICACIÓN, EL POT

El plan de ordenamiento territorial (POT) es el mecanismo básico del planeamiento físico-jurídico-económico del territorio. Para el municipio es de obligatorio cumplimiento su aplicación, ya que sus decisiones son vinculantes a corto, medio y largo plazo. Por esto, la Ley 388 define un conjunto de objetivos, políticas, metas, programas y normas para orientar el desarrollo físico del territorio y la utilización del suelo.

El POT, que tiene tres componentes: general, urbano y rural, define los usos del suelo y las dotaciones físicas de los municipios. Dadas las diferencias en tamaños de los municipios, la Ley 388 establece distintas normas, entre ellas: los POT para municipios con poblaciones mayores a 100.000 habitantes, planes básicos de ordenamiento territorial para municipios entre 30.000 y 100.000 habitantes y los esquemas de ordenamiento territorial para municipios con población menor a 30.000 habitantes.

El nivel de determinaciones del POT se concreta a través de los planes parciales, los cuales son unidades físicas integradas de planeación y ordenación del territorio, en los que se definen los usos del suelo, la dotación de servicios públicos, los índices de edificabilidad, los índices de ocupación del suelo.

\section{EL PLAN DE ORDENAMIENTO TERRITORIAL DE CALI (POT, 2000)}

En el ámbito local, el POT es el mecanismo mediante el cual se plantean líneas de desarrollo de la ciudad de forma planificada. Por ello, los cambios en la legislación nacional para el ordenamiento territorial (Ley 388 de 1997) han establecido que la gestión del espacio físico se debe adelantar a partir de la estructuración del espacio público. Ahora bien, el modelo del POT para la ciudad de Cali genera una propuesta hacia la consolidación de una ciudad región, o un modelo territorial, mediante la articulación de un sistema vial interregional consolidado, en el cual se tienen en cuenta, entre otros, el sistema ambiental y paisajístico (Departamento Administrativo de Planeación Municipal de Santiago de Cali, 2000, p.1).

Por otro lado, el modelo urbano indica e identifica a la ciudad de Cali, a partir de una serie de áreas en las cuales se desarrollan diversas actividades, que les permite relacionarse entre sí, con el fin de lograr desarrollos y evolucionar de acuerdo con los cambios en las condiciones socioeconómicas, políticas y administrativas de la ciudad; entre estas se encuentra la central urbano-regional, marcada desde sus inicios por la concentración y aglomeración de actividades comerciales, y políticoadministrativas; la oriental, la occidental, el sur y la zona de posible expansión. 


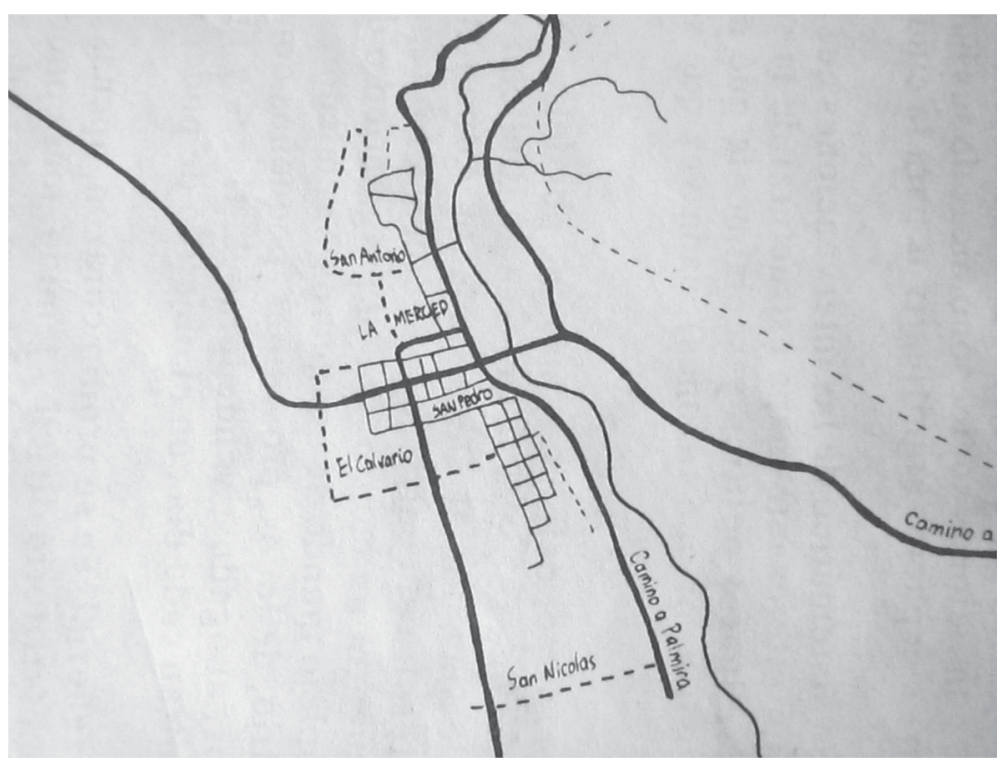

Figura 1. Mapa de Cali en sus inicios, centro principal.

Fuente: Centro de Investigación y Documentación Socioeconómico-CIDSE- (1995).

En los criterios que sustentan este modelo se encuentra que sus puntos más relevantes son los siguientes: la recuperación del centro tradicional histórico como eje regional y urbano, la generación de subcentros como efecto de la descentralización de actividades, y la conformación de un sistema de transporte masivo para integrar a la ciudad en términos de costos (tiempo y dinero).

El modelo espacial urbano descrito en el POT organiza la urbe a partir del centro histórico e institucional, anexando a este una serie de centralidades de segundo nivel y sus respectivos subcentros según sean sus funciones y actividades: comerciales, industriales o de servicios (Departamento Administrativo de Planeación Municipal de Santiago de Cali, 2000, p. 3), con la finalidad de desconcentrar las actividades del centro principal y a este mismo, y ordenar las dinámicas originadas en la periferia y su correcta relación con el centro.

Es por ello, que el POT busca la vigencia de sus contenidos a corto, medio y largo plazo. A largo plazo, se tiene en cuenta el correspondiente a tres periodos constitucionales de las administraciones municipales, es decir, nueve años. A medio plazo, tiende a seis años, y a corto plazo a tres años. En este sentido, la definición de programas y proyectos de los planes de desarrollo de los municipios tendrán en cuenta el medio y largo plazo de ocupación del territorio. 
Dentro de las operaciones estructurantes trazadas por el POT, en líneas generales, se presenta el desarrollo de un área metropolitana conurbada, sustentada bajo la constitución de una ciudad monocéntrica nodal, empero, no se considera como tal el desarrollo monocéntrico, sino el fortalecimiento de una urbe policéntrica (Avendaño, 2003, p. 45). Lo cual se puede ver reflejado en la infraestructura vial trazada, en cuanto plantea la estructuración del parque tecnológico en el sur, la revitalización de la industria regional en el oriente, así como el traslado a la periferia de los usos institucionales y la conformación de un sistema de transporte masivo, que permita relacionar los subcentros con el centro principal. Debido a esto, el POT planteó centralidades de segundo, tercer y cuarto orden con respecto a su importancia, con el objeto de articular sectores que por su localización generan efectos de valorización. Entre estas se encuentran (Departamento Administrativo de Planeación Municipal de Santiago de Cali, 2000, p. 37):

\section{- Centralidad de Nivel I:} la urbano-regional

\section{- Centralidad de Nivel II:} centro de servicios y comercio
- Centralidad de Nivel III: central de distribución de alimentos: galerías

\section{- Centralidad de Nivel IV:}

C.A.L.I.: intersecciones viales, estaciones

Dentro de ese proceso de conformación de la ciudad se debe tener en cuenta la demanda futura de tierra urbana. En este sentido, es cierto que se consideró el aumento de densidad histórica dentro del área urbana desarrollada, teniendo en cuenta que su aumento en el período 1979-1999 fue del 2,36\% anual, inferior al 2,87\% estimado por el Pideca (Departamento Administrativo de Planeación Municipal, 1980) para el período (Departamento Administrativo de Planeación Municipal de Santiago de Cali, 2000, p. 8).

Con base en los datos sobre la participación de los usos del suelo, la tendencia sobre generación de vías tiende a reducirse en $10 \%$ y a aumentar en $12 \%$ el uso en actividad residencial, y en $4 \%$ en equipamiento institucional en los siguientes años, teniéndose proyección hasta el 2021. 


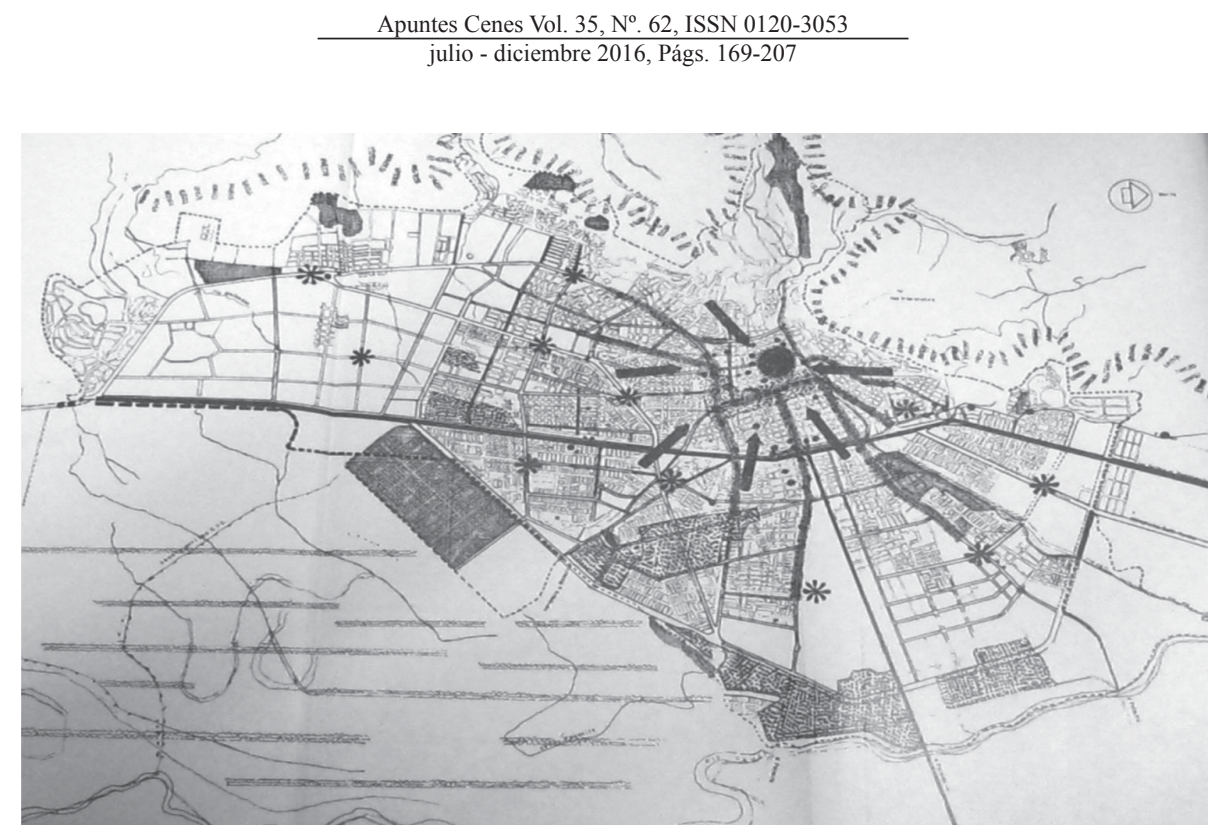

Figura 2. Plano del Plan General de Desarrollo de Cali y su área metropolitana 1970-1985. Fuente: Departamento Administrativo de Planeación Municipal de Cali (2000)

Tabla 1. Participación porcentual de los usos del suelo, Cali 1969-2021

\begin{tabular}{|l|c|c|c|}
\hline USOS & $\mathbf{1 9 6 9}$ & $\mathbf{1 9 9 0}$ & $\begin{array}{c}\text { 2021 SEGÚN } \\
\text { TENDENCIA }\end{array}$ \\
\hline Residencial & 39,1 & 46,0 & 54,3 \\
Industrial & 3,5 & 2,7 & 1,7 \\
Comercio/Servicios & 4,1 & 4,4 & 4,6 \\
Vías & 37,1 & 29,4 & 19,4 \\
Zonas verdes & 7,6 & 6,0 & 4,0 \\
Equipamiento institucional & 8,6 & 11,4 & 16,0 \\
\hline
\end{tabular}

Fuente: Planeación Municipal Cali - POT 2000. 


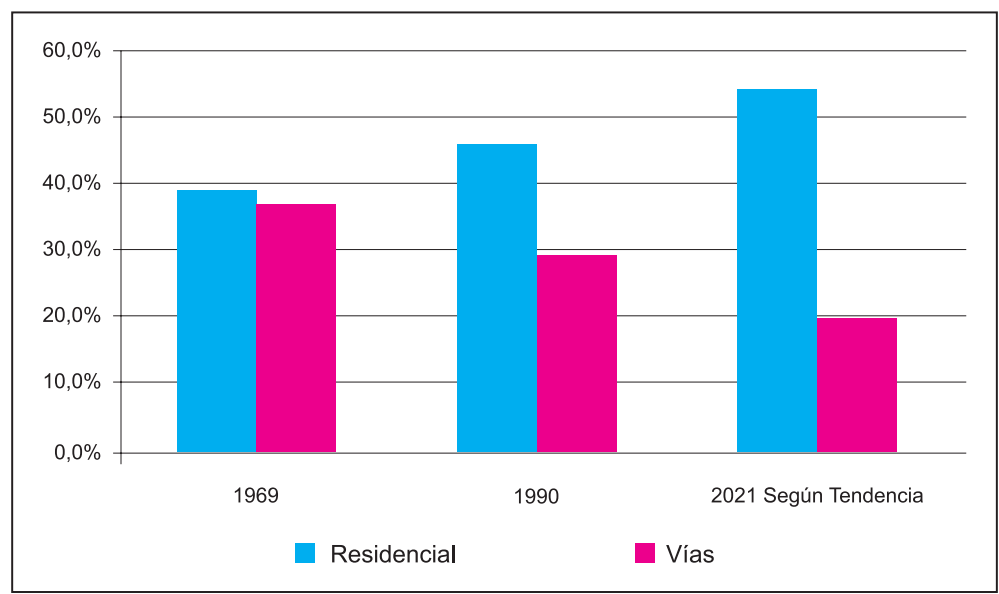

Figura 3. Participación porcentual usos del suelo Cali (1969-2021).

Fuente: Planeación Municipal Cali - POT 2000.

Entre sus puntos positivos se encuentra el integrar la cordillera Occidental a la urbe, captando desde una perspectiva ecológica el desarrollo al tratar de establecer la zonificación cerca de los pulmones ambientales existentes. Pese a esto, el aspecto ambiental carece de un diagnóstico como tal, por lo cual no tiene presentes programas pertinentes para la recuperación y reubicación de la población que reside en los márgenes de los ríos Cauca y Cali (Coronel, 1999, p. 22), ni incluye acciones de atención y prevención sobre los riesgos por incendios forestales, zonas de amenaza, fallas y riesgos, lo cual es preocupante dado que algunas de las zonas de expansión se encuentran en laderas y terrenos inundables o sobre fallas tectónicas.

De igual manera es destacable el replanteamiento que se ha originado desde los años cincuenta con el plan piloto, pasando por el PDG de 1969 y el Pideca de 1979 sobre Cali y su desarrollo lineal, promoviéndola como un corredor industrial y de exportación al estar cercana al puerto de Buenaventura. En relación con el tema del POT, el columnista Néstor Fabián Ruiz del periódico La Palabra planteó lo siguiente; "sean estos aciertos o desaciertos, basta recordar que el POT se debe a que Cali tiene una fuerte clase dirigente (por no decir burguesa) que al ver la danza de los millones escondida en el plan no dudó en meterle mano, ya que aquí no le dan trabajo, vivienda, salud, y educación a nadie. Por lo tanto, el dinero y el poder lo han tenido siempre los mismos" (Ruiz, 2000, p. 13).

La situación anterior es explicable porque algunos terratenientes, industriales y políticos poseen la tierra hacia donde la ciudad va a crecer. Sin embargo, frente a estas situaciones, el POT plantea la 
expansión de la urbanización en un esquema que continúa lo que ha sido la tendencia en la ocupación estratificada del espacio urbano. Por lo tanto, el ordenamiento territorial de Cali debe y no puede ser de otra manera, un ordenamiento metropolitano, en el cual estén presentes todos los actores involucrados en el diseño, formulación e implementación de políticas públicas urbanísticas.

\section{DESARROLLO URBANO 1999-2008}

La diversificación en la expansión residencial y comercial suscitada tanto en el norte como en el sur de la ciudad, e igualmente el aumento del volumen habitacional en el casco urbano, tras la integración de los sectores como el Distrito de Aguablanca y de la zona baja de la ladera, entre los cuales se encuentran Terrón Colorado, Alto Nápoles, El Aguacatal, El Jordán y Los Chorros, junto con el cambio institucional ocasionado por el proceso de descentralización administrativa en el ámbito público y la elección popular, modificaron la composición de la estructura urbana durante los años ochenta, época en la que se configuró el concepto de comunas.

Al igual que en otros municipios de Colombia, las comunas, en el caso específico de la ciudad de Cali, estaban reglamentadas con base en el Acto Legislativo n. ${ }^{\circ} 1$ de 1986, en el Decreto 1333 del mismo año y la Ley 11 de 1986 que en su artículo 16 concedió facultades a los concejales para dividir el territorio de sus respectivas ciudades en zonas que se denominaron comunas para el área metropolitana y de corregimientos para las zonas rurales.

En 1988 el Concejo Municipal mediante el Acuerdo 015 estableció la sectorización del municipio de Cali organizándose el área urbana en 20 comunas y 15 corregimientos. Así mismo, dicho estatuto dejó en claro que las comunas carecerían de personería jurídica propia, autonomía administrativa y patrimonio independiente.

Al llegar a los años noventa, pese a la sectorización y el control urbano, se incrementaron los niveles poblacionales $\mathrm{y}$ de hacinamiento, $\mathrm{y}$ con esto aumentó de igual modo el déficit de vivienda, llegando a una cifra igual a 118000 y sin tener áreas de expansión para vivienda popular, lo cual empeoraba como respuesta a la caída del sector de la construcción. Mientras tanto, el $50 \%$ de los barrios de la ciudad con problemas de aglomeración se ubicaba en las comunas $7,9,10,11,12$ y 20 , y se preveía que gran parte de las áreas marginales evidentemente sufriría del fenómeno del hacinamiento.

A lo anterior se suma el hecho, poco tratado en el POT, de las zonas de alto riesgo, las cuales aumentaron y para el año 1987 estaban habitadas por el 21 $\%$ de la población, una relación igual a uno de cada cinco habitantes (Alcaldía de Santiago de Cali, 1998, p. 17). Como se puede observar en la Tabla 2, en el periodo de 1987-1995 aumentó en un 
$40 \%$ el área urbanizada, aunque la población se redujo alrededor del $23 \%$.

En el periodo siguiente (entre 1995-2004) la tendencia cambió y el área urbana solo creció $1.3 \%$, lo que explica la caída del sector de la construcción; de igual forma, la población aumentó en un $25 \%$, lo cual indica que con respecto al crecimiento de población, el área efectiva ocupada crecía en forma menos proporcional, evidenciando un déficit habitacional.

Tabla 2. Cali, indicadores del área neta y la población.

\begin{tabular}{|c|c|c|c|c|c|c|}
\hline Año & Población & $\begin{array}{c}\text { incremento } \\
\text { \% }\end{array}$ & $\begin{array}{c}\text { Área- } \\
\text { hectáreas }\end{array}$ & $\begin{array}{c}\text { incremento } \\
\text { \% }\end{array}$ & $\begin{array}{c}\text { Densidades } \\
\text { (hab/hect) }\end{array}$ & $\begin{array}{c}\text { incremento } \\
\%\end{array}$ \\
\hline 1969 & 794.866 & 4187,2 & & 189,8 & & \\
1978 & $1 ' 148.350$ & 44,5 & 6553,0 & 56,5 & 175,2 & $-7,7$ \\
1987 & $1 ' 536.534$ & 33,8 & 8545,2 & 30,4 & 179,8 & 2,6 \\
1995 & $1 ' 886.360$ & 22,8 & 11938,6 & 39,7 & 158,0 & $-12,1$ \\
2004 & $2 ' 369.696$ & 25,6 & 12089,3 & 1,3 & 196,0 & 24,1 \\
\hline
\end{tabular}

Fuente: cálculos propios con base en Plan General de Desarrollo (1969), Pideca (1980).

Cali en cifras, Departamento Administrativo de Planeación Municipal (2004).

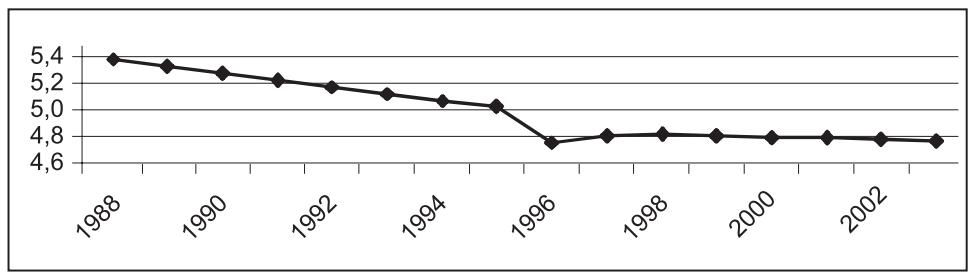

Figura 4. Densidad (habitantes / viviendas).

Fuente: Plan General de Desarrollo (1969), Pideca (1980). Cali en cifras, Departamento Administrativo de Planeación Municipal (2004). Cálculos propios.

Si bien es cierto que la Figura 4 nos ratifica lo expresado anteriormente, la densidad (habitantes/viviendas) ha estado disminuyendo gradualmente durante los últimos años, como consecuencia del rezago del sector de la construcción. A esto se suma que los barrios aprobados durante el período descrito ni siquiera alcanzan en promedio la cifra del $1 \%$. Ahora bien, durante los últimos 15 años, el total de viviendas en la ciudad de Cali solo creció en promedio alrededor del $3 \%$ anual ${ }^{4}$.

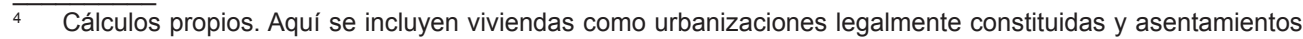
ilegales.
} 
Por otro lado, aunque Cali fue en su momento una ciudad monocéntrica, la estructura urbana hoy tiende a desconcentrarse generando nuevos puntos nodales en la periferia. En respuesta a esa situación podemos resaltar los siguientes aspectos: que la mitad de la población empleada está en el centro y la zona nororiental, específicamente comunas dos, tres y cuatro, cuyos usos del suelo son de uso mixto, comerciales. Debido a esto tiene baja calidad ambiental, por la emisión de partículas toxicas de las industrias, del parque automotor, sumado a la poca cultura ambiental de la comunidad y las instituciones estatales.

La zona norte no es ajena a actividades de tipo industrial, por lo que los sectores medios y altos vinculados a esta actividad demandaban zonas residenciales aledañas sobre el sector de la Avenida Sexta. Dado esto, el uso residencial es igual al $48.1 \%$ (30.8 viviendas por hectárea) del área en la comuna 2, ocupando los usos comerciales y de servicios el $7.2 \%$ a lo largo de los ejes viales y residenciales de estratos económicos altos, con sectores comerciales como Chipichape, Éxito La Flora, la 14 de Sameco, entre otros, que han surgido en las últimas dos décadas. Solo el $10.5 \%$ representa áreas libres, el $8.6 \%$ la zona de uso institucional, $1.52 \%$ zona industrial, y el $7.61 \%$ el recreativo, el mismo valor para áreas verdes (The World Bank, 2003, p. 25).

Uno de los problemas más sentidos de estas comunas es la actividad de polución ambiental, debido a la cercanía de las fábricas y sus emisiones nocivas a la atmósfera, que, por ende, traen complicaciones a los habitantes, que se traducen en dificultades para conciliar el sueño, pues no pueden respirar el aire que llega directamente, ya que trae consecuencias para la salud (Alcaldía de Santiago de Cali, 1998, p. 40).

La diversificación en la estructura espacial generó múltiples polos empresariales en diferentes áreas de la urbe. Un claro ejemplo de esto es como la micro y pequeña empresa se ubican tradicionalmente en el centro principal, concentrando el $32.4 \%$ de las empresas de Cali. Por su parte, el Comité de Planificación Territorial estimó que las tres cuartas partes de la zona centro son ocupadas por industrias, como: Bavaria, Lloreda Grasas, Colgate Palmolive y Kraft, lo que también ha significado un deterioro ambiental. También se encuentran la planta de asfaltos del municipio, las industrias de hipoclorito y las salsamentarias.

Porotraparte, hay un grannúmerodetalleres de reparación de vehículos, empresas metalmecánicas, establecimientos comerciales de repuestos. Sin embargo, es importante señalar que gran parte de la fuerza de trabajo proviene de otros sectores de la ciudad. En este sentido, ser zona industrial no le representa ningún beneficio significativo, en cambio, sí agudiza la situación de los habitantes por el gran deterioro ambiental. Entre 1990 y 1999 surgió una nueva conciencia y esta zona central progresó visiblemente. Por ejemplo, una vez cerrado el matadero 
municipal, años después se construyó Comfandi el Prado, dotando de un mejor aspecto y valorización al sector.

El modelo de desarrollo (Departamento Administrativo de Planeación Municipal, 2000) planteó para el sur de la ciudad una articulación mediante el Sistema Integrado de Transporte MIO de Metrocali y el sistema arterial urbano, a esta integración conectarían un Parque Tecnológico (Universidad San Buenaventura), un Centro de Exposiciones (Unicentro) y centros educativos que aumentaran la oferta de instituciones universitarias. De esta manera, en el eje articulador se consolidan centros nodales que generan economías de escala y mediante los cuales se basa la valorización de la zona, tales como Cosmocentro, Palmetto Plaza, Clínica Materno Infantil, Clínica Santillana, La 14 de la carrera 70 con calle $5^{\mathrm{a}}$, el Éxito, La 14 de Pasoancho, Carrefour, Makro, Clínica Valle del Lili, Universidad del Valle, Unicentro, Centro Jardín Plaza, Holguines Trade Center, Centro Comercial Aventura Plaza y las Universidades Icesi, Javeriana y Autónoma.

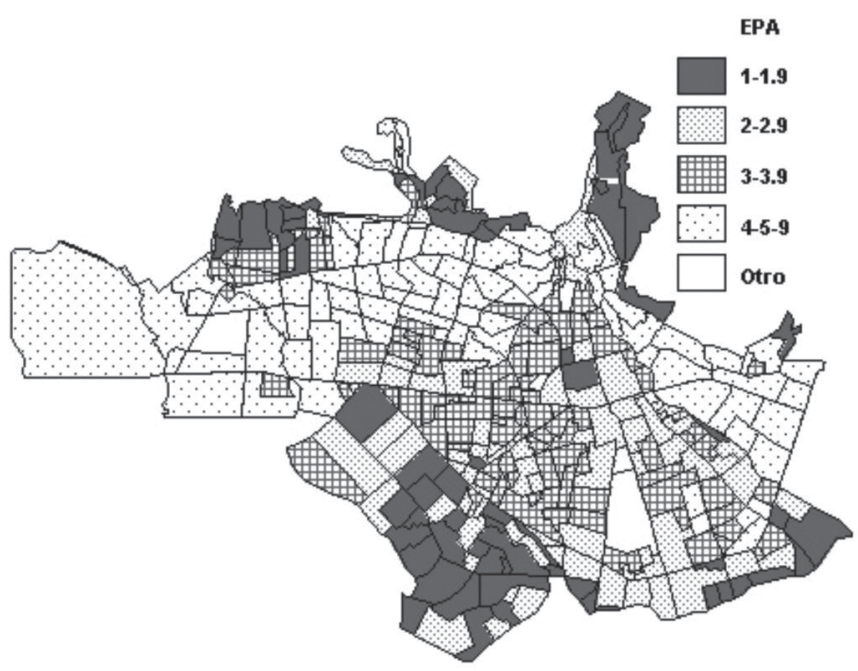

Figura 5. Distribución de barrios en Cali según estrato promedio ajustado (EPA).

Fuente: Pradilla, Alberto et al. (2007).

Por lo tanto, la zona del sur, como espacio propicio para la expansión residencial, desarrolló la mayor actividad del sector de la construcción, destinando la oferta a familias con ingresos superiores, es decir, de estratificación media-alta y alta.
De igual modo, es preocupante la creciente densificación de características ilegales en los cerros bajos de la ciudad, debido a que la dotación de servicios no es pertinente por las condiciones geográficas, por lo cual el municipio no puede invertir en estas zonas. 
Por otro lado, a finales de la década de los setenta, las tasas de crecimiento vegetativo de la población empezaban a desacelerarse continuamente, como también el área efectiva ocupada. En consecuencia, era de esperarse que la relación habitantes/hectáreas tendiera a disminuir, lo que indicaba una limitación en la oferta de vivienda y por ende, un descenso en la urbanización. Así mismo, esto conllevaba una disminución en la cobertura de los servicios públicos, la cual es explicada por la relación viviendas-servicios totales. Para el año 1979, se genera una expansión poblacional, fruto de las migraciones que determinaron un crecimiento atípico en la estructura urbana, desarrollando lo que se conoce comúnmente como el Distrito de Aguablanca.

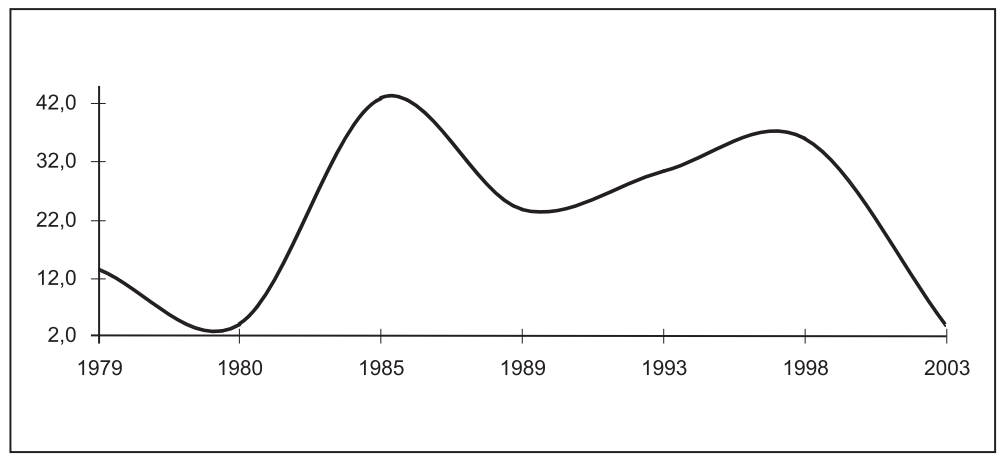

Figura 6. Cobertura de servicios públicos en Cali, 1979-2003.

Fuente: cálculos propios con base en Planeación Municipal.

La Figura 6 nos muestra oscilaciones que son significativas en la cobertura de los servicios públicos en la ciudad de Cali. Para 1980, la Figura describe una tendencia creciente, explicada por las inversiones de Emcali en el sector oriental, como también el desarrollo de políticas de la empresa, tales como ${ }^{5}$ : el Plan Quinquenal, el Plan Maestro I, Plan Maestro II y el Plan Maestro III, en busca del desarrollo del Distrito de Aguablanca.

Como se puede notar en la Figura 6, entre 1980 y 1993 hay un crecimiento considerable en la cobertura, alrededor del $131 \%$. A partir de 1998, se origina el periodo de la crisis de Emcali, lo cual se refleja en una disminución en términos de cobertura de servicios públicos. En efecto, entre 1998 y 2003 la cobertura se incrementó solo en $3.8 \%$.

Para finalizar, se encontró una relación fuerte entre la población total y el número de suscriptores de los servicios públicos, cuya cifra es del orden del $92.7 \%$, durante los últimos 16 años.

\footnotetext{
5 Para el desarrollo de este tema se tuvo en cuenta el libro de Miguel Camacho Aranguren (2006), sobre la historia de los servicios públicos en la ciudad de Cali.
} 


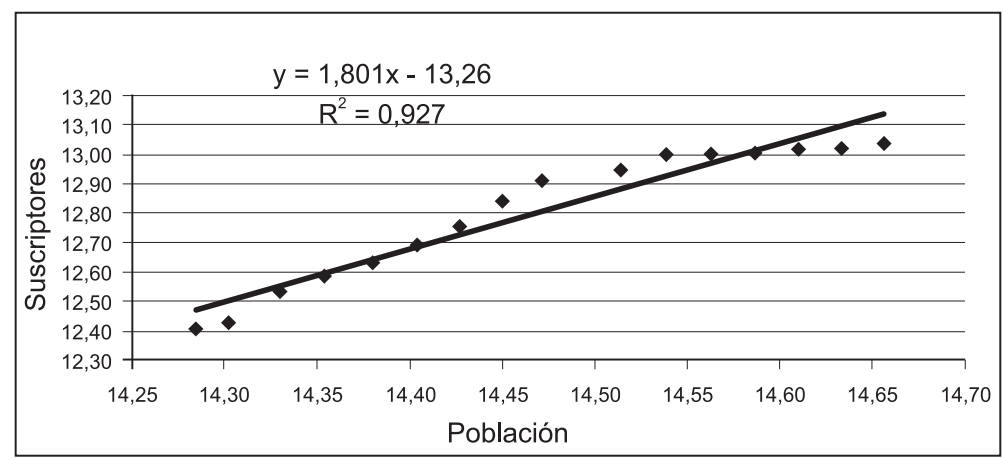

Figura 7. Relación Población y Suscriptores de Servicios Públicos Fuente: cálculos propios con base en Emcali.

\section{INFLUENCIA DEL POT EN LA CIUDAD DE CALI (2008)}

Por todo lo planteado anteriormente, el POT ha propuesto en términos normativos una ciudad equilibrada que busca reestructurar las relaciones entre sus piezas o zonas (Departamento Administrativo de Planeación Municipal de Cali, 2000), cualificando las funciones de su centro tradicional y promoviendo un sistema de centralidades que pueden corroborarse a través de las futuras estaciones del MIO, los centros de atención local integrada (C.A.L.I.), las estaciones de Policía, los múltiples centros de salud y los puntos de comercio que la ciudad hoy tiene. Todo esto permite una desconcentración de actividades secundarias y terciarias haciéndolas más accesibles a la población.

No obstante, el uso del suelo para actividades terciarias rezaga el desarrollo metropolitano, según lo argumentan los planificadores urbanos. Esta distorsión implica que el uso terciario urbano expulsa constantemente a la población metropolitana hacia desarrollos cada vez más periféricos (Valderruten, 1999, p.31).

La incapacidad de reconocer la tendencia actual hacia desarrollos en los satélites o nuevas localidades de Cali, ha impedido una búsqueda de soluciones a las demandas de vivienda de los sectores de medio-bajo y bajos ingresos en los proyectos institucionales públicos, lanzando a estos sectores a nuevos asentamientos periféricos con mala infraestructura en servicios públicos.

En relación con lo anterior, existe evidencia de que las soluciones expansivas como en el caso de la ciudad de Cali, producen una reducción sensible en términos de bienestar, lo cual permite comprobar que la vivienda de interés social no es tan adecuada a la satisfacción de necesidades como pareciera.

Así mismo, lo que sí es fehaciente es la injusta decisión de recostar a los 
pobres contra las áreas inundables del río Cauca, como también contra las fallas geográficas de las laderas de la ciudad, lo cual indica de esta situación que es una vieja costumbre de la visión segregacionista como excluyente, en la cual los pobres están condenados a vivir en las zonas de más alto riesgo y marginalidad.

Hoy, la dirección propuesta por el POT apunta al crecimiento de la ciudad hacia el sur. No obstante, este podría extenderse un poco más hacia el noroccidente, donde ya hay redes de infraestructura o también hacia el oriente, donde hay grandes globos de terreno disponible.

Igualmente, como se puede notar en la Figura 8, el incremento de barrios se ha mantenido constante desde el año 2000 a razón de 250 , con lo cual no ha habido hasta la fecha un aumento significativo en el número de barrios.

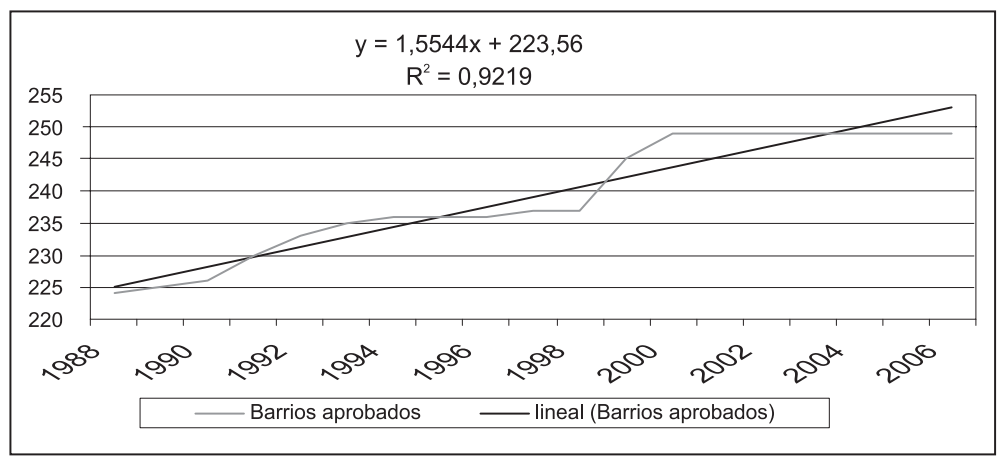

Figura 8. Incremento de barrios aprobados en la ciudad de Cali.

Fuente: Cali en Cifras. Planeación Municipal Cali.

Basta recordar que la ampliación del perímetro urbano ha ido a la zaga de la ocupación ilegal de los terrenos periféricos (Velasco, 1999, p. 34). Es decir, si se hubieran aplicado estrategias hace treinta años, se hubieran evitado los costos sociales y económicos de asentamientos en lugares donde el suministro de servicios públicos costó más que si los procesos de urbanización se hubiesen realizado en forma planificada. Por esto, como consecuencia de las herencias del pasado, la reorientación de Cali está actualmente más reglamentada. Sin embargo, los contribuyentes del fisco municipal todavía pagan los costos de urbanización de Aguablanca (Velasco, 1999, p. 35). No hay que olvidar que los beneficiarios de esta miopía institucional fueron los propietarios de extensiones, quienes generaron una situación de oligopolio que hizo aumentar los precios de la tierra por encima de su productividad social marginal.

Por otra parte, en términos de la infraestructura vial y de transporte, el POT se 
equivocó con la famosa Avenida de los Cerros como solución norte-sur, ya que esta ruta no respondió a las expectativas debido al alto flujo vehicular en las horas pico. En ese mismo orden, el sistema integrado de transporte masivo (MIO de Metrocali) ha sido una obra totalmente inconstante, en la cual para 2008 solo había entrado en funcionamiento el primer tramo de tan enorme inversión.

El alcance del POT 2000 proyectaba una continuación de los desarrollos anteriores, planteando a Cali como eje articulador regional mediante el corredor vial Yumbo-Cali-Jamundí, con dos puntos de importancia Centro-Norte y Centro-Sur, estos como jalonadores de multitudes poblacionales, integrando a la vez una serie de subcentros. Lo cual se puede vislumbrar a partir del trazado en la infraestructura vial del SITM y su comparación con la densidad poblacional de la ciudad. De esta manera, se plantean centros principales como Centro, donde está la estación con el mismo nombre, con características institucionales, comerciales, y de servicios; Norte, con la estación Menga, con el fin de articular la población que llega desde Yumbo, y articula a la población con la zona industrial y de servicios; Sur, donde se encuentra la estación Universidades, que recibe a la población de Jamundí y articula la población con los complejos universitarios, comerciales y de servicios; Oriente con la estación Andrés Sanín; así como estaciones secundarias como Unidad Deportiva y Cañaveralejo en el Sur, Calima en el Norte, y Nuevo Latir en el oriente. Presentando con esta distribución una serie de centralidades tanto de primer como de segundo orden, según la densidad poblacional.

Académicos e investigadores del tema urbanístico afirman que el tren ligero o el tranvía moderno hubiesen sido beneficiosos en términos sociales, económicos y financieros para la ciudad (Arboleda, 1999, p. 45), debido a que la infraestructura de rieles del pasado aún permanecía como testigo inerte en algunas zonas de la urbe, con lo cual los costos y la iniciación del proyecto hubiesen sido más eficaces y efectivos en términos de bienestar. Sin embargo, lo más sencillo y práctico frente a la complejidad del transporte, hubiera sido la reestructuración del sistema de buses y la ampliación de las vías de Cali. 

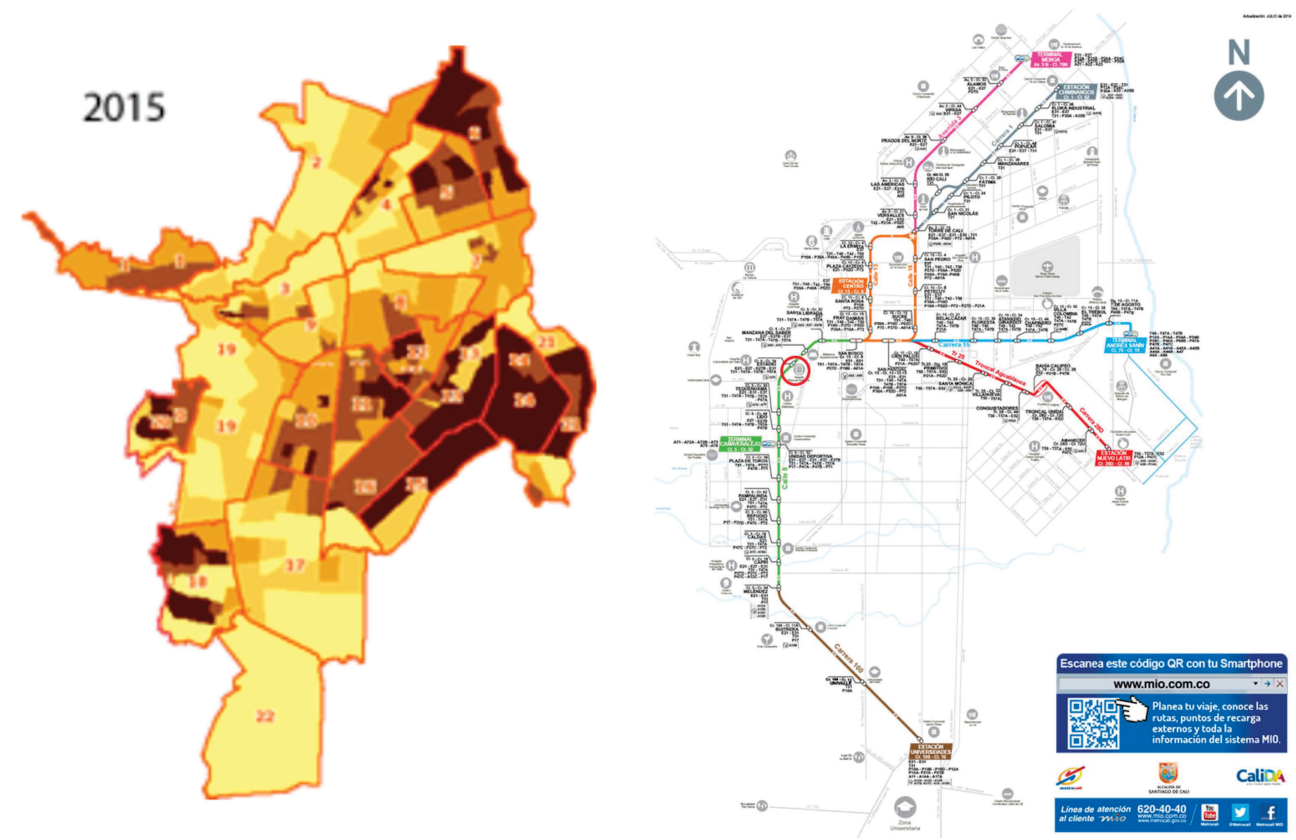

Figura 9. Comparación entre mapa de Cali, densidad poblacional e infraestructura vial del sistema integrado de transporte masivo (MIO)

Fuente: mapa esquemático troncal del MIO (Departamento Administrativo de Planeación Municipal, 2012), rutas del MIO (Cali, 2015)

EVALUACIÓN EX POST DE LAS POLÍTICAS PÚBLICAS URBANÍSTICAS DE LA CIUDAD DE CALI, (1968-2008): UNA APROXIMACIÓN CUANTITATIVA

La evaluación ex post es la identificación sistemática de los efectos que una política pública, llámese programa, proyecto o acción, tiene sobre los individuos, los hogares, las instituciones y el medio ambiente. Por lo tanto, la evaluación ex post apoya decisiones sobre expansión, modificación o eliminación de proyectos, programas o políticas, e igualmente, compara la eficiencia de distintas opciones de una política pública.

Este tipo de evaluación, dentro de una actitud clínica, busca conocer las diferencias entre la meta planeada y la meta lograda. Por ende, da más importancia a uno o más parámetros que se encuentran en similitud con el objetivo que persigue la política pública y no presta atención alguna a los efectos que su implementación haya podido tener en otros parámetros. Ahora bien, dentro de una actitud normativa se busca medir los resultados obtenidos a la luz de 
valores seleccionados, para entrar en el debate político y normativo, asumiendo una posición crítica en relación con la teoría de cambio social asociada con la política pública (Vargas, 2009, p. 142) Lo relevante en esta metodología es la contrastación entre objetivos y finalidades de una política pública dentro de la cual se desarrolla la misma. En últimas, una evaluación es un hecho sobre un dato con referencia a un valor (Meny \& Thoenig, 1992).

En el caso de la ciudad de Cali, la política pública urbana del Plan General de Desarrollo (1969), el Pideca (1980) y el Plan de Ordenamiento Territorial (2000) han tenido como objetivo común la desconcentración cronológica o periodizada de actividades, sean estas comerciales, industriales y de servicios, por fuera del centro histórico institucional tradicional o CBD (Center Business District). Por tal razón, la evaluación por realizar de estas políticas, estará enfocada en el análisis cuantitativo de dichas propuestas.

A efectos de la evaluación, se aplicarán modelos econométricos propios de la economía regional y urbana, con respecto a la eficacia en la centralización o descentralización de la urbe. Es cierto que este tipo de evaluación debe corresponder a la lógica de modelos, en este caso de la econometría espacial urbana, para estudiar si el objetivo de la política pública es coherente y se correlaciona con el comportamiento o la tendencia que predice el modelo.

Por tal motivo, en la evaluación de las políticas mencionadas se estimará el modelo de Edwin Mills ${ }^{6}$ (1972) con ciertos cambios que permiten utilizarlo dinámicamente en series de tiempo y en datos tipo panel; todo esto teniendo como variables los precios de la tierra en el período 1959-2001 y las distancias físicas a los distintos centros.

El modelo de Mills tiene por objeto analizar ciudades monocéntricas, deviene de modelos de economía espacial clásicos y pioneros dentro de esta rama, los cuales parten del modelo original de Von Thûnen, debido a lo cual, tiende a describir entre otros aspectos una relación inversa entre el precio y la distancia al centro o subcentros que tenga la ciudad, con lo cual se genera una función exponencial decreciente, basada teóricamente en que los precios más altos de la tierra se encuentran en el centro o subcentros, ya que estos concentran la mayoría de las actividades económicas a las que los individuos o firmas desean acceder. Funcionalmente el modelo se escribe así:

$$
\log \operatorname{Pr}=B o+\beta_{1} \log D
$$

6 Para mayor apreciación del tema véase Burbano (2003). El trabajo de Burbano hace un aporte al tema del monocentrismo urbano, sin embargo, presenta regresiones con problemas de autocorrelación y heterocedasticidad. 
Donde $B_{1}<0$, se denomina gradiente precio-distancia, el cual indica el porcentaje de disminución en el precio del suelo a medida que el lote i-ésimo se encuentra a mayor distancia del DCC, $B_{0}$ es el precio medio del suelo en el DCC, $P i$ es el precio del lote i-ésimo y $D$ es la distancia entre este y el DCC. Trabajar con un modelo log-log lleva implícito el reconocimiento de elasticidades. En este sentido un modelo estimado en logaritmos (por ejemplo con una única exógena) implica:

$$
\log Y_{i}=\hat{\beta}_{0}+\hat{\beta}_{1} \log X_{1 t}+u_{i}
$$

Si bien, puede observarse que, matemáticamente el parámetro $\beta_{1}$ es la derivada parcial de " $\log \left(\mathrm{X}_{1 i}\right)$ " respecto a " $\log \left(\mathrm{Y}_{i}\right)$ ":

$$
\hat{\beta}_{1}=\frac{\partial \log Y_{i}}{\log X_{i}}
$$

O lo que es igual:

$$
\hat{\beta}_{1}=\frac{\partial \log Y_{i}}{\partial \log X_{i}}=\frac{\frac{\Delta Y_{i}}{Y_{i}}}{\frac{\Delta X_{1 i}}{X_{1 i}}}
$$

Si observamos esta expresión, podemos decir que el parámetro es algo similar a la elasticidad de $\mathrm{Y}_{\mathrm{i}}$ sobre $\mathrm{X}_{1 \mathrm{i}}$. Por tanto, los parámetros de un modelo en logaritmos son especialmente útiles, dado que la elasticidad es un concepto de notable utilidad en el análisis de la relación existente entre dos variables (porcentaje de movimiento de la $\mathrm{Y}$ frente a un movimiento del $1 \%$ en la variable $\mathrm{X}$ ). A partir de un modelo con especificación $\log$ - $\log , \beta_{1}$ es la elasticidad de $Y$ con respecto a $X$ (Wooldrige, 2001, p. 655), en este caso la variable $Y$ corresponde a la variable dependiente, o sea el precio de la tierra urbana. La $X$ se refiere a las variables independientes o explicativas, como la distancia al centro o subcentros que tenga una ciudad.

Resulta conveniente indicar que las elasticidades, en este caso, la relación precio-distancia, determinan las fuerzas de atracción hacia el centro o centros dentro de una urbe, es decir, establecen el valor de la zona o punto referencial, como también los efectos centralizadores de los atributos del tamaño del mercado y concentración de los mismos en los diferentes centros. En relación con los precios de la tierra para la ciudad de Cali, los datos se recopilaron a través de la información suministrada por la Lonja de Propiedad Raíz como también por Planeación Municipal. Estos precios fueron convertidos a pesos constantes, lo cual se realizó a través del deflactor del PIB de 1998. 


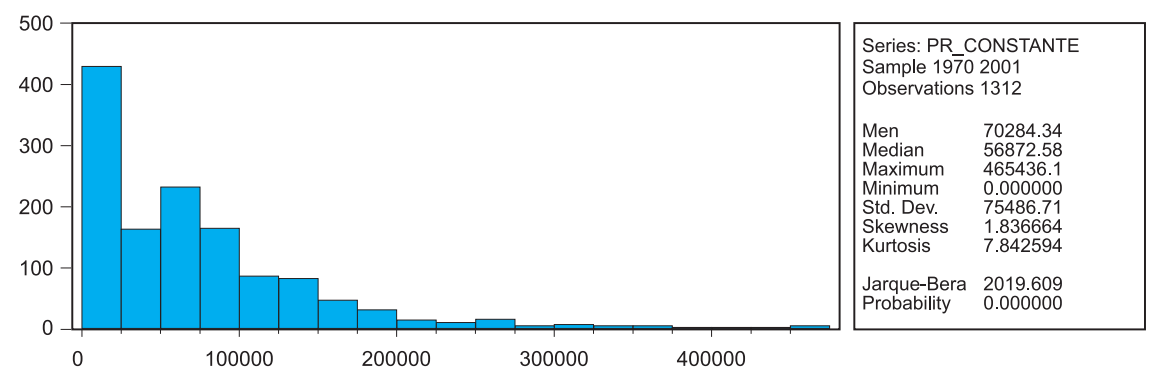

Figura 10. Estadísticas de los precios de la tierra urbana.

Fuente: cálculos propios con base en Planeación Municipal.

Tabla 3. Distribución de los precios de la tierra

Tabulation of PR CONSTANTE

Date: 04/18/09 Time: 10:11

Sample: 19702001

Included observations: 1312

Number of categories: 5

\begin{tabular}{|l|c|c|c|c|}
\hline Value & Count & Percent & $\begin{array}{c}\text { Cumulative } \\
\text { Count }\end{array}$ & $\begin{array}{c}\text { Cumulative } \\
\text { Percent }\end{array}$ \\
\hline$[0,100000)$ & 990 & 75.46 & 990 & 75.46 \\
{$[100000,200000)$} & 249 & 18.98 & 1239 & 94.44 \\
{$[200000,300000)$} & 45 & 3.43 & 1284 & 97.87 \\
{$[300000,400000)$} & 20 & 1.52 & 1304 & 99.39 \\
{$[400000,500000)$} & 8 & 0.61 & 1312 & 100.00 \\
\hline Total & 1312 & 100.00 & 1312 & 100.00 \\
\hline
\end{tabular}

Fuente: cálculos propios con base en Planeación Municipal.

Como se puede notar en la Tabla 3 y en las estadísticas de los precios de la tierra (Figura 10), hay una alta dispersión entre la media y la mediana. Así mismo, el coeficiente de variación lo ratifica (107.4 $\%$ ), por lo tanto estamos ante una distribución poco concentrada. El sesgo nos indica una frecuencia con cola a la derecha y la curtosis genera una distribución leptocúrtica. El 99 \% de la distribución tiene valores inferiores a 400.000 pesos.

Hay que tener en cuenta que en este tipo de modelos de econometría espacial comúnmente existen problemas de autocorrelación y heterocedasticidad, por lo tanto deben corregirse antes de ser presentados. 
Ahora bien, para el caso de una estructura espacial policéntrica, McDonald y Prather-: citados por (García \& Muñiz, 2005) muestran diferentes ejemplos del tema. Por ello, en el propósito de nuestra evaluación se muestra la siguiente ecuación:

$$
\ln D\left(d_{C B D}\right)=\ln D_{0}-\gamma d_{C B D}+\delta d^{-1}{ }_{C B D}+\varepsilon
$$

Es decir, en relación con la ecuación de arriba, ahora incluimos una nueva variable, donde $(\delta S U B d-1)$ es la inversa de la distancia al subcentro más próximo y $\delta$ su gradiente correspondiente. Trabajar con una distancia directa, para el caso del CBD, y una distancia invertida, para el caso del subcentro más próximo, implica reconocer la influencia espacial del $\mathrm{CBD}^{7}$.

Según Wooldrige (2001), al realizar una estimación tipo panel con efectos fijos se eliminan factores inobservables constantes en el tiempo. Para corregir posibles problemas de heterocedasticidad en los modelos, estos deben ser calculados por el método de White. De igual manera, para corregir los problemas de autocorrelación se introduce un término AR (1) con el ánimo de generar una tendencia estacionaria en la serie precio de la tierra urbana.

Hoy, el POT plantea la presencia de siete centralidades (de cuatro niveles) entre las que incluye: el centro tradicional histórico institucional, los centros comerciales, las edificaciones institucionales, los escenarios deportivos y la plaza de toros, las galerías, los C.A.L.I. y las estaciones del sistema de transporte (Departamento Administrativo de Planeación Municipal de Cali, 2000, p. 38). Vale aclarar que, muy a pesar de dichas indicaciones, solo tomamos a criterio dos subcentros o puntos diferentes del centro tradicional que por su importancia generan mayores fenómenos valorizantes y fuerzas de atracción gravitatoria notorias, ellos son:

En primer lugar, el Centro Norte (LDN), ubicado en la intersección de la avenida $3^{\mathrm{a}}$ norte con calle 70 en la glorieta del puente de Sameco. Este punto es de especial importancia, porque es el cruce de vías importantes, incluídas la intermunicipal Cali-Yumbo. De igual forma, esta zona es de alta actividad industrial, por concentrarse allí muchas de las empresas e industrias que ofrecen el empleo para los municipios antes mencionados. Se tuvo en cuenta también, porque los centros comerciales y supermercados del sector están muy cercanos en términos de tiempo.

En segundo lugar, el Centro Sur (LDS), se estableció en el área de la calle $5^{\mathrm{a}}$ entre calle 13 y carrera 100. Este centro es relevante, porque allí se ubican centros comerciales y universidades, los cuales atraen a gran cantidad de personas como efecto de viajes pendulares. Además, esta es una vía intermunicipal al estar conectada con el corredor Cali-Jamundí.

Agradezco las observaciones y sugerencias generadas por el profesor Harvy Vivas Pacheco, las cuales enriquecieron el propósito de este estudio. 
Para nuestra primera evaluación, (ver Tabla 4) tomamos en cuenta los tres centros para saber si cumplen con lo planteado en el PGD, respecto a la descentralización de la ciudad.

\section{Tabla 4.}

Dependent Variable: LPR?

Method: Pooled Least Squares

Date: 06/20/08 Time: $11: 18$

Sample (adjusted): 2230

Included observations: 146 after adjustments

Cross-sections included: 3

Total pool (unbalanced) observations: 371

White period standard errors \& covariance (d.f. corrected)

Convergence achieved after 9 iterations

\begin{tabular}{|l|c|c|c|c|}
\hline Variable & Coefficient & Std. Error & t-Statistic & Prob. \\
\hline C & 7.271178 & 0.812230 & 8.952113 & 0.0000 \\
LDN? & 0.015065 & 0.208471 & 0.072265 & 0.9424 \\
LD & -0.677889 & 0.054132 & -12.52287 & 0.0000 \\
LDS? & -0.136099 & 0.065453 & -2.079352 & 0.0383 \\
LA & 0.087324 & 0.015586 & 5.602692 & 0.0000 \\
AR(1) & 0.761272 & 0.028669 & 26.55359 & 0.0000 \\
Fixed Effects & & & & \\
(Cross) & -0.000507 & & & \\
1970--C & -0.215609 & & & \\
1975--C & 0.199677 & & & \\
1979--C & & & \\
\hline
\end{tabular}

Effects Specification

Cross-section fixed (dummy variables)

R-squared

Adjusted R-squared

S.E. of regression

Sum squared resid

Log likelihood

Durbin-Watson stat
0.827856

0.824537

0.316622

36.39054

$-95.71498$

1.905245
Mean dependent var

S.D. dependent var

Akaike info criterion

Schwarz criterion

F-statistic

Prob(F-statistic)
6.523938

0.755871

0.559110

0.643557

249.3864

0.000000

Fuente: cálculos propios con base en Planeación Municipal. 
Ciertamente, lo planteado por el Plan General de Desarrollo (1969) indicaba que la ciudad de Cali durante los años setenta estaba haciendo una transición al monocentrísmo nodal, ya que el subcentro sur (LDS) tiene una probabilidad inferior al $5 \%$, siendo esta estadísticamente significativa. Por lo tanto, las elasticidades indican que a medida que nos alejamos del centro sur en un kilómetro, el precio de la tierra tiende a disminuir en un $13 \%$.

No obstante, el centro histórico tradicional (LD) tiene una preponderancia mayor, debido a que su elasticidad indica que a medida que nos alejamos del centro referencial, el precio de la tierra disminuye en $67 \%$. El centro norte (LDN) no es por ahora significativo.

El área construida en los barrios (LA) tiene una relación directa con el precio por metro cuadrado (LPR), ya que cuando se incrementa el área construida del barrio en $1 \%$, su precio se valoriza en $87 \%$. También, el modelo tiene un buen ajuste, se explica aproximadamente en un $83 \%$ de su variación total y conjuntamente es significativo.

Para la Tabla 5, se puede decir que lo relevante de esta evaluación indicaba que el centro tradicional (LD) no era tan preponderante. La acción de las fuerzas del mercado desde mediados y hacia finales de los años setenta empezaba a mostrar su efectividad, dado que las tendencias indican que desde 1959 el precio de la tierra en el centro va disminuyendo marginalmente, y sus coeficientes así lo expresan. En este sentido, la Figura 12 muestra también como los picos de los precios de la tierra en el centro histórico tradicional van decreciendo entre los años 1963, 1974 y 1979 .

Por otra parte, existe una relación directa entre el ingreso familiar per cápita y el precio de la tierra urbana; es decir, a medida que se incrementa en $1 \%$ el ingreso familiar (LIF), así mismo, el precio de la tierra se incrementa en 53 $\%$. Ello indica que hay coherencia entre el ingreso y los asentamientos urbanos. Como se puede notar, el $88 \%$ de su variación está explicado por los precios de la tierra. También, el modelo es significativo individual y conjuntamente.

Ahora, al analizar la Figura 12 por períodos, podemos darnos cuenta cómo fue en lo sucesivo el desarrollo urbanístico. Como se puede notar, el precio promedio de la tierra en la ciudad de Cali disminuyó en los años ochentas, entre otras causas por la sobreoferta del mercado generado por la expansión del Distrito de Aguablanca. También, el aumento del precio durante el primer lustro de los años noventa se explica por el boom de la construcción generado, en parte, por la filtración de los dineros del narcotráfico. Este fenómeno permitió la diversificación de distintos sectores de la ciudad. 


\section{Tabla 5.}

Dependent Variable: LP?

Method: Pooled EGLS (Cross-section weights)

Date: 06/20/08 Time: 11:21

Sample (adjusted): 2229

Included observations: 142 after adjustments

Cross-sections included: 6

Total pool (unbalanced) observations: 611

Iterate coefficients after one-step weighting matrix

Convergence achieved after 10 total coef iterations

\begin{tabular}{|l|c|c|c|c|}
\hline Variable & Coefficient & Std. Error & t-Statistic & Prob. \\
\hline C & 2.878207 & 0.205234 & 14.02405 & 0.0000 \\
LD & -0.425387 & 0.045484 & -9.352519 & 0.0000 \\
LIF & 0.531132 & 0.024638 & 21.55771 & 0.0000 \\
1959--@TREND & -0.003241 & 0.001542 & -2.101959 & 0.0360 \\
1963--@TREND & -0.003978 & 0.001605 & -2.478838 & 0.0135 \\
1970--@TREND & -0.000899 & 0.000911 & -0.987063 & 0.3240 \\
1974--@TREND & -0.002961 & 0.000732 & -4.044455 & 0.0001 \\
1975--@TREND & -0.001320 & 0.000633 & -2.085688 & 0.0374 \\
$1979--@ T R E N D$ & 0.002384 & 0.000661 & 3.606695 & 0.0003 \\
AR(1) & 0.633151 & 0.027553 & 22.97936 & 0.0000 \\
\hline
\end{tabular}

Weighted Statistics

\begin{tabular}{|l|l|l|l|}
\hline R-squared & 0.883404 & Mean dependent var & 6.685281 \\
Adjusted R-squared & 0.881658 & S.D. dependent var & 1.339816 \\
S.E. of regression & 0.283610 & Sum squared resid & 48.34138 \\
F-statistic & 505.9504 & Durbin-Watson stat & 2.290613 \\
Prob(F-statistic) & 0.000000 & & \\
\hline
\end{tabular}

Unweighted Statistics

\begin{tabular}{|l|l|l|l|}
\hline R-squared & 0.882986 & Mean dependent var & 6.415673 \\
Sum squared resid & 48.51477 & Durbin-Watson stat & 2.249061 \\
\hline
\end{tabular}

Fuente: cálculos propios con base en Planeación Municipal. 


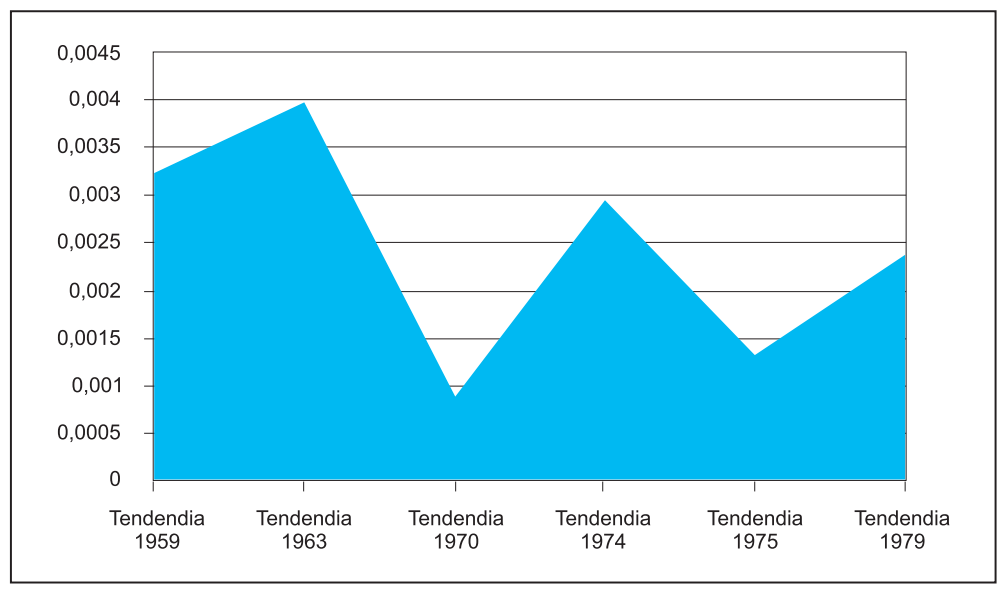

Figura 11. Tendencia de los precios de la tierra en el centro tradicional. Fuente: cálculos propios con base en Planeación Municipal

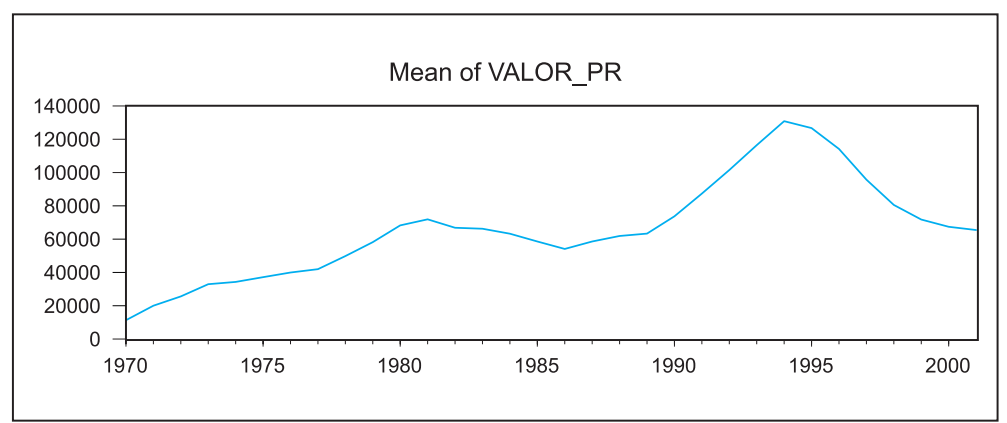

Figura 12. Media de los precios de la tierra en la ciudad de Cali. Fuente: cálculos propios con base en Planeación Municipal 
Tabla 6.

Dependent Variable: PRECIO

Method: Panel Least Squares

Date: 06/20/08 Time: 11:55

Sample (adjusted): 19712001

Cross-sections included: 144

Total panel (balanced) observations: 4464

Convergence achieved after 8 iterations

\begin{tabular}{|l|c|c|c|c|}
\hline Variable & Coefficient & Std. Error & t-Statistic & Prob. \\
\hline DTN1 & -4.542157 & 1.642350 & -2.765645 & 0.0057 \\
DTN2 & -4.106292 & 1.543277 & -2.660762 & 0.0078 \\
DTN3 & -3.831465 & 1.466045 & -2.613470 & 0.0090 \\
DTN4 & -4.003109 & 1.422991 & -2.813165 & 0.0049 \\
TN1 (1970-1980) & 123175.4 & 10749.80 & 11.45839 & 0.0000 \\
TN2 (1981-1989) & 122414.5 & 10097.33 & 12.12345 & 0.0000 \\
TN3 (1990-1994) & 113846.2 & 9619.870 & 11.83448 & 0.0000 \\
TN4 (1995-2001) & 128203.7 & 9265.382 & 13.83685 & 0.0000 \\
AR(1) & 0.945234 & 0.004372 & 216.2210 & 0.0000 \\
\hline
\end{tabular}

\begin{tabular}{|l|c|l|l|}
\hline R-squared & 0.922711 & Mean dependent var & 71672.86 \\
Adjusted R-squared & 0.922572 & S.D. dependent var & 64953.60 \\
S.E. of regression & 18073.91 & Akaike info criterion & 22.44434 \\
Sum squared resid & $1.46 \mathrm{E}+12$ & Schwarz criterion & 22.45725 \\
Log likelihood & -50086.77 & Durbin-Watson stat & 1.412253 \\
\hline Inverted AR Roots & .95 & & \\
\hline
\end{tabular}

Fuente: cálculos propios con base en Planeación Municipal.

Ahora, como se puede ver en el modelo, los precios del centro de la ciudad, como su gradiente distancia, caen período a período. Así mismo, el $92 \%$ de su variación está explicado por su variable dependiente. En últimas, el modelo es significativo individual y conjuntamente.

Por otro lado, el cambio en la urbe, originado por el fenómeno de la construcción, consolidó la aparición de subcentros que estaban siendo determinados y analizados en 1999 durante el proceso de formulación de la política pública del Plan de Ordenamiento Territorial. Es decir, en el momento de la implementación del Plan, ya se preveía la desconcentración de actividades en la ciudad de Cali.

Con esto se quiere plantear que las fuerzas del mercado han generado polos de desarrollo en la urbe, como consecuencia 
de dispersión y desconcentración de actividades por fuera del centro tradicional, para buscar con ello, la valorización de otros sectores, los cuales pueden corroborarse a través de las estimaciones econométricas aquí realizadas.

Tabla 7.

Dependent Variable: LP?

Method: Pooled Least Squares

Date: 06/20/08 Time: 18:18

Sample (adjusted): 19712001

Included observations: 1240 after adjustments

Cross-sections included: 33

Total pool (balanced) observations: 40920

Convergence achieved after 3 iterations

\begin{tabular}{|l|c|c|c|c|}
\hline Variable & Coefficient & Std. Error & t-Statistic & Prob. \\
\hline LD & -0.648145 & 0.104713 & -6.189731 & 0.0000 \\
LDS & -0.534229 & 0.048584 & -10.99596 & 0.0000 \\
LDN & -1.434284 & 0.096874 & -14.80562 & 0.0000 \\
AR(1) & 0.900050 & 0.001726 & 521.6163 & 0.0000 \\
\hline
\end{tabular}

\begin{tabular}{|l|c|l|l|}
\hline R-squared & 0.870394 & Mean dependent var & 8.456305 \\
Adjusted R-squared & 0.870384 & S.D. dependent var & 4.909915 \\
S.E. of regression & 1.767677 & Akaike info criterion & 3.977307 \\
Sum squared resid & 127849.5 & Schwarz criterion & 3.978150 \\
Log likelihood & -81371.70 & Durbin-Watson stat & 1.931463 \\
\hline
\end{tabular}

Fuente: cálculos propios con base en Planeación Municipal.

Por lo tanto, como se puede analizar a través de esta evaluación, la consecución sistemática y continua en las políticas de desarrollo urbanístico (PGD, Pideca y POT) en pro de la descentralización urbana, generó a largo plazo, la consolidación de subcentros (ya establecidos por efectos del mercado) en la ciudad, que nos llevan a plantear que hoy Cali es una ciudad con tendencia policéntrica. 


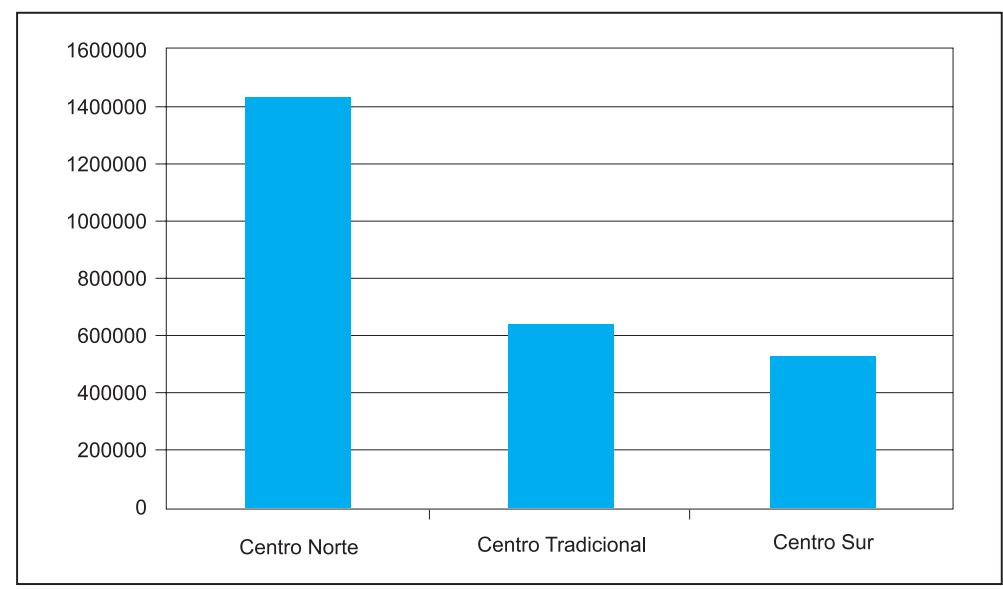

Figura 13. Centros calculados en la ciudad de Cali. Fuente: cálculos propios con base en Planeación Municipal

Además, es de especial importancia el centro norte, ya que al alejarse de allí, los precios de la tierra disminuyen en $143 \%$, con lo cual se plantearía que la zona industrial de Sameco tiene hoy las mayores rentas, lo cual se explica por ser el uso residencial o industrial un factor cada vez más escaso en esa zona (ver Figura 13). Le seguiría el centro tradicional, que explica que a medida que se alejan de él, en cualquier dirección, el precio disminuye en $65 \%$. Finalmente, el centro sur de la ciudad muestra una elasticidad precio-distancia del $53 \%$.

El modelo econométrico demuestra que los centros estimados son significativos individual y conjuntamente (sus p-valores son menores que 0,05). El modelo es robusto, ya que el $87 \%$ del coeficiente de determinación indica que la variabilidad explicada es alta.
En síntesis, los propósitos de la política pública urbanística de Cali en los últimos 40 años se orientaron a la desconcentración de actividades industriales, comerciales y de servicios. Evidentemente, esto se ha logrado, sin embargo, el mayor impacto de desarrollo en la urbe y su descentralización obedece más a las fuerzas del mercado que a las propias políticas (corroborado por los ejercicios econométricos anteriormente expuestos).

\section{CONCLUSIONES}

El desarrollo metropolitano de Cali ha mostrado desde los años cincuenta una recepción de desplazados por la violencia, lo cual ha conducido, desde esa época, a un aumento del crecimiento demográfico que tuvo épocas de estancamiento hacia finales de los años sesenta. En 1969, se inicia en la urbe el primer plan o política 
pública de desarrollo urbanístico (PGD), que buscaba estimular las inversiones públicas y privadas con el ánimo de generar el desarrollo de la ciudad, como también, cambiarle la estructura física, con ocasión de los VII Juegos Panamericanos. Aspectos coyunturales (como el Upac) y estructurales (como la política pública nacional de: "las cuatro estrategias, la construcción como sector líder" de la Administración Pastrana Borrero) impactaron en la urbe.

Ahora bien, el Plan General de Desarrollo (PGD, 1969) planteó la distribución Yumbo- Cali-Jamundí, como eje articulador del Área Metropolitana, el cual involucra la integración de estas poblaciones por motivos de pendularidad, explicados por los viajes intermunicipales entre el trabajo y el hogar. Así mismo, se planteó una expansión hacia el sur como parte del área de futuro desarrollo de la urbe, entre otras razones porque el norte de la ciudad tenía limitaciones de tipo ambiental, generadas por la contaminación de las empresas ubicadas en el corredor Cali-Yumbo. Por lo tanto, la propuesta del Plan General es un tipo de ciudad lineal, la cual debe responder a la dotación de servicios públicos y a la reestructuración del sistema de transporte.

Es decir, para las décadas en mención, esta decisión de política pública urbanística implicó que en nuestra ciudad el proceso de las tendencias, su intensidad y organización espacial habían definido dos ciudades en condiciones físicas, sociales y económicas distintas, a las cuales había que aplicarles soluciones también diferentes. Mientras que para la ciudad pudiente, que creció norte-sur, hubo que aplicar medidas organizativas que controlaran el proceso de expansión, para el centro tradicional el problema tendía a la saturación y su respuesta era la desconcentración o descentralización de actividades.

El punto neurálgico del Pideca fue la no planificación de la zona más degradada del oriente de la ciudad. Es decir, el Distrito de Aguablanca fue la opción que dio albergue a la población desplazada, la cual se ubicó en esta zona deprimida, rompiendo con el modelo urbanístico propuesto para la ciudad por el Plan General de Desarrollo del año de 1969. Por otra parte, la alternativa propuesta por el Pideca no hizo más que prolongar las tendencias reales del desarrollo urbanístico; es decir, al capital comercial trasladarse hacia el sur, buscó valorizar la zona de mayor desarrollo de la ciudad. La cuestión fue simple: la planeación de Cali solamente continuó hacia el futuro el desarrollo espontáneo que generó el capital.

El modelo urbano del POT identifica a la ciudad de Cali, como un conjunto de áreas: la central urbano-regional, la oriental, la occidental, la del sur y la pieza de expansión. Igualmente, recomienda al área urbana y de expansión, la continuación del desarrollo lineal nortesur, teniendo en cuenta el mejoramiento de la zona oriental. Dentro de los criterios que sustentan este modelo se encuentra 
que sus puntos más relevantes son la recuperación del centro tradicional histórico como eje regional y urbano, la generación de subcentros como efecto de la descentralización de actividades y la conformación de un sistema de transporte masivo para integrar a la ciudad en términos de costos (tiempo y dinero).

Si bien, el modelo espacial urbano planteado por el POT identifica un centro principal, histórico e institucional, articulado por centroides, núcleos de segundo nivel o subcentros de dispersión de actividades, sean estas comerciales, industriales o de servicios, bajo esta misma lógica se busca la desconcentración de actividades tanto en las instituciones públicas como en las privadas.

Finalmente, vale indicar que todos estos planes estaban acompañados entre sí por la búsqueda a largo plazo de la descentralización de la ciudad. Pero, realmente su impacto fue marginal, debido a que son las fuerzas del mercado las que imponen el desarrollo de la urbe. En este sentido, el Plan de Ordenamiento Territorial de Cali se equivoca en la conformación de "centralidades". Por ejemplo, las normas plantean que un estadio, un puesto de salud, un escenario deportivo, una estación de policía, una plaza de toros, una estación del sistema integrado de transporte (MIO), y una galería, son señalados aisladamente como un centro. Valoración que no es cierta, debido a que la aglomeración de actividades en un punto neurálgico como puede ser la zona Univalle, Unicentro, El Ingenio y Ciudad Jardín-Pance (centro sur, estimado en el presente estudio), atraen y expulsan muchas más personas que los centros establecidos por el POT.

Por lo tanto, al realizar la evaluación de estas políticas públicas se encontró lo siguiente: la ejecución de las políticas de desarrollo urbanístico (PGD, Pideca y POT) en pro de la desconcentración urbana, generó a largo plazo, la consolidación de subcentros ya establecidos en la ciudad que nos llevan a plantear que hoy Cali es una ciudad con tendencia policéntrica. De igual manera, la evidencia empírica ratifica que, en mayor grado, la presión de las fuerzas del mercado ha marcado un gran impacto que determina indiscutiblemente el rumbo y el desarrollo de la ciudad. Su evaluación en este caso, las regresiones econométricas así lo validan, con lo cual se responde a las preguntas planteadas al inicio del presente estudio.

\section{DEDICATORIA}

Dedico este trabajo a todos los estudiantes con los cuales he compartido estos años de docencia e investigación universitaria. 


\section{REFERENCIAS}

Alcaldía de Santiago de Cali. (1998). Programa ciudadano Cali que queremos. Resumen ejecutivo. Cali.

Arboleda, G. (1999). Estudio plan vial y de transporte de la ciudad de Cali. Cali: Departamento Administrativo de Planeación Municipal.

Avendaño, M. L. (2003, enero-junio). Plan de Ordenamiento Territorial de Cali. La idea de ciudad y la norma. Revista Ciencias Humanas Universidad San Buenaventura, Volumen, 6(1).

Burbano, J. E. (2003). Análisis del sostenimiento de la estructura urbana monocéntrica en la ciudad de Cali. Tesis Economía. Universidad del Valle, Cali.

Calero, F. (1972). Socio-Economic Analysis of the Urban Settlement Pattern in Cali, Colombia. Thesis MSc in Urban Geography. Southern Illinois University.

Cali-2015 (2015). Mapa esquemático troncal del MIO. Rutas del MIO. Recuperado de http://cali2015.co/cali/transporte-publico/

Camacho, M. G. (2006). La encrucijada de los servicios públicos en Cali (1961-1991). Cali: Imprenta Departamental del Valle del Cauca.

Coronel, J. (1999). El POT debe concretarse. El Plan de Ordenamiento Territorial de Cali; Qué opinan los urbanistas y planificadores. Revista CITCE: Territorio, Construcción y Espacio, (2).

Corporación Regional del Valle del Cauca (CVC). (2004). Génesis y desarrollo de una visión de progreso. Cali: CVC.

Departamento Administrativo de Planeación Municipal. (1985). Antecedentes y motivos del plan de ordenamiento territorial. Cali.

Departamento Administrativo de Planeación Municipal. (1988, junio). Resumen y diagnósticos sectoriales. Cali.

Departamento Administrativo de Planeación Municipal. (1990). De la desagregación del plan de desarrollo municipal en su versión comunitaria. Cali. 
Departamento Administrativo de Planeación Municipal. (2000, sep.). POT de Cali. Documento Resumen. Cali.

Departamento Administrativo de Planeación Municipal. (2004). Cali en cifras. Santiago de Cali.

Departamento Administrativo de Planeación Municipal. (2012). Mapa densidad poblacional. Recuperado de http://www.cali.gov.co/planeacion/publicaciones/ noticias_2012_pub

Espinosa, L. D. (2006). Plan Piloto de Cali 1950. Bitácora, 1(10).

García, M. A. \& Muñiz, I. (2005, abril). Descentralización del empleo; ¿Compactación policéntrica o dispersión? El caso de la Región Metropolitana de Barcelona (1986- 1996). Documento de trabajo. España: Universitat Autónoma de Barcelona, Facultat de Ciencies Economiques i Empresarials.

Giraldo, F. (1997). La política y la ciudad. Bogotá: Escuela Superior de Administración Pública (ESAP).

Giraldo, F. (1989). Reforma urbana y desarrollo social. Bogotá: Camacol.

Jiménez, N. (2005). Desastres por inundaciones y deslizamientos en Cali, 1950-2000. Tesis para optar por el título de Historiadora. Universidad del Valle. Cali.

Meny, I. \& Thoenig, J. C. (1992). Las políticas públicas. Barcelona: Ariel.

Ministerio de Desarrollo Económico. (1995). Ciudades y ciudadanía: la política urbana del salto social. Bogotá: MDE.

Moncayo, E. (2004). Nuevos enfoques del desarrollo territorial: Colombia en una perspectiva latinoamericana. Bogotá: Universidad Nacional de Colombia, Red de Estudios de Espacio y Territorio (RET).

Mosquera, G. (2011). Expansión urbana y políticas estatales en Cali. Revista Polis, Observatorio de Políticas Públicas.

Naciones Unidas y Departamento Nacional de Planeación. (1986). Disponibilidad de tierras y cuantificación de necesidades de servicios públicos. Capitulo III. Cali: DNP. 
Planeación Municipal de Cali. (1971, mayo). Plan general de desarrollo de Cali (PGD) y su área metropolitana 1970-1985-2000. Cali: Oficina de Planeación Municipal de Cali.

Planeación Municipal de Cali. (2000, sep.). POT Cali. Propósitos, principios, objetivos, estrategias y politicas que orientan el ordenamiento territorial. Documento resumen. Cali: Oficina de Planeación Municipal de Cali.

Pradilla, A. et al. (2007). Determinantes de salud y políticas públicas: identificación de indicadores de problemas de salud y factores asociados, basada en datos disponibles. Colombia Médica, 38(3). Recuperado de http://colombiamedica. univalle.edu.co/index.php/comedica/article/view/508/988

Ruiz, N. F. (2000, 1 de abril). EL POT: esto es cuestión de pandebono. Columna de Opinión. La Palabra, Periódico de la Universidad del Valle.

The World Bank. (2003). Cali, Colombia toward a city development strategy. En; http://documents.worldbank.org/curated/en/2002/01/1808690/cali-colombiatoward-city-development-strategy

Valderuten, O. (1999). De ordenamientos, reordenamientos y planificación. El Plan de Ordenamiento Territorial de Cali; Qué opinan los urbanistas y planificadores. Revista CITCE: Territorio, Construcción y Espacio, (2).

Vargas, A. (1999). Notas sobre el estado y las políticas públicas. Bogotá: Almudena.

Velasco, L. M. (1982). Historia del hábitat vallecaucano. 1532-1982. Cali: CVC.

Velasco, J. (1999). Algunos comentarios. El Plan de Ordenamiento Territorial de Cali; Qué opinan los urbanistas y planificadores. Revista CITCE: Territorio, Construcción y Espacio, (2).

Vergara, R. (2009). El desarrollo de la estructura fisico-urbana en la ciudad de Cali (1968-2008). Un caso de análisis de política pública. Tesis Maestría en Políticas Públicas. Universidad del Valle, Cali.

Wooldrige, J. (2001). Introducción a la econometría. México: Thompson Learning. 